\title{
Effect of Hip Abductors and Lateral Rotators Muscle Strengthening on Pain and Functional Outcome in Patients with Patellofemoral Pain: Systematic Review and Meta-Analysis
}

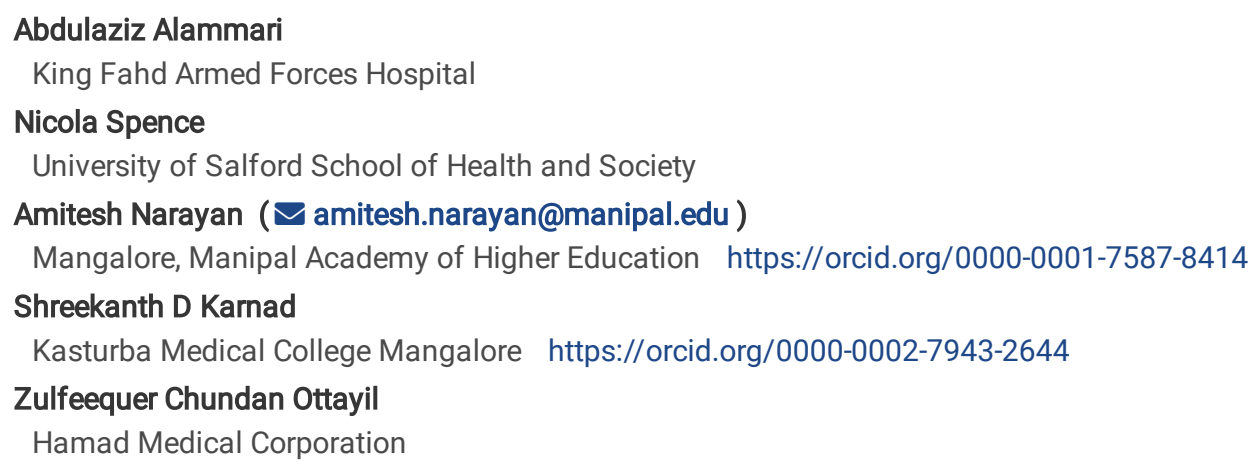

Keywords: Patellofemoral pain, patellofemoral pain syndrome, Anterior Knee Pain, Hip and Quadriceps and Hip muscles strengthening, Knee function, Systematic reviews, Randomised Controlled Trials.

Posted Date: August 10th, 2021

DOI: https://doi.org/10.21203/rs.3.rs-778213/v1

License: (c) (i) This work is licensed under a Creative Commons Attribution 4.0 International License. Read Full License 


\section{Abstract}

Background: This study systematically reviews and Meta-analyses the best-published evidence on the therapeutic value of strengthening hip abductors and lateral rotators muscles for the treatment of Patellofemoral Pain (PFP) with a presumptive hypothesis that strengthening hip muscles stabilises the patellofemoral joint, relieves pain and enhances knee functions.

Methodology: Electronic database searches of Medline, EMBASE, CINAHL, PEDro and PubMed Central between January 1994 and September 2019 using PICOS tool. The methodological quality of the selected studies was appraised individually using the 20-item McMaster Critical Review Form for Quantitative Studies. Supplemental quality appraisal of randomized controlled clinical trials performed using the Cochrane Collaboration's 'Risk of bias' quality criteria. Data on patient population demographics, interventions, duration of intervention and outcome measures were extracted, summarized in evidence tables and descriptive analysis made. Pooled effects size from appropriate RCTs was determined by meta-analysis under both fixed and random-effects models.

Results: All included fourteen studies demonstrated that hip muscles strengthening resulted in improved pain and knee function. All RCTs, except one, demonstrated that hip muscles strengthening is superior to quadriceps strengthening. Of the five RCTs accessing the surplus effect of hipquad versus quadriceps strengthening, four suggested that hip-quad strengthening is superior over the standard quadriceps strengthening alone to improve PFP and knee function.

Conclusion and Implications: In patients with PFP, strengthening of hip abductors and lateral rotators have greater therapeutic significance than the conventional quadriceps exercises in improving knee pain and function both in the short- and long term. However, caution is required, because a standardized hip-quad protocol is yet to be developed, which warrants further studies.

\section{Systematic review registration:}

There was no protocol prepared and no amendments were present. This systematic review is registered under Open Science framework, with following registration digital object identifier 10.17605/OSF.IO/CWZ8V

\section{Introduction}

Patellofemoral pain (PFP) is characterised by anterior knee pain emanating from the patellofemoral joint involving patella and fibrous tissue on the medio-lateral retinaculum [1]. The aetiology is irregular patellar kinematics due to excessive pressure on the patellofemoral joint coupled with poor proximal neuromuscular control and hip muscle weakness [2-4]. The pain in PFP is because of inflammation coupled with damage to bony, cartilaginous or the connective tissues of the patellofemoral joint $[1,2,5]$.

The PFP incidence rate is $25-40 \%$ of all cases of anterior knee pain which is considerably high. Hence, therapeutic interventions are imperative to reduce permanent knee disabilities and improve quality of life [5-7]. The prevalence of PFP is higher in women and athletes than males (2:1) and is even higher (4:1) among athletes [6].

The works of literature on musculoskeletal injuries indicate a positive correlation between hip muscles weakness and PFP [8-10]. In a case report on PFP, authors noted that excessive hip adduction coupled with the weakness of the hip extensors and abductors are predominantly musculoskeletal concerns [10]. The current physiotherapy evidence strongly supports quadriceps muscle strengthening as an effective strategy to improve overall knee function in patients with PFP [11-13]. The proximal hip muscles exercises reported to be effective in relieving patellofemoral pain and improving knee function when compared to knee exercises alone [14]. Therefore, strengthening these muscles underlies the objective treatment of PFP. While quadriceps strengthening is already the standard physiotherapeutic target for PFP, it is plausible that strengthening of hip muscles will serve greater benefits, because of its effect on greater control over the knee biomechanics $[5,15]$.

\section{Relationship between Hip Muscles (abductors and external rotators) Strength and PFP}

Muscles of the hip (hip abductors and external rotators) are essential for knee and pelvic stabilization during ambulation [5]. The hip abductors and external rotators act synergistically to eccentrically control the hip adduction and internal rotation movements, respectively [15-17]. The diminished strength of hip abductors and external rotators muscles may result in poor neuromuscular control during activities that necessitate loading on the patellofemoral joint $[5,8,18]$. The weak hip abductors may cause excessive femoral adduction, thereby, augmenting lateral forces (Knee Valgum) acting on the patella [19]; while, weak hip external rotators results in unrestricted internal rotation of the femur, that augments contact pressure between the lateral facet of the patella and lateral femoral condyle [19]. Hence, weak hip muscles (mainly hip abductors and external rotators) is an important aetiological factor for PFP $[5,15,20,21]$.

Many studies compared the effectiveness of hip muscles strength in patients with PFP to matched healthy controls [16, 21-23]. Ireland et al. reported eccentric muscle strength reduction of $26 \%$ in hip abductors and $36 \%$ in hip external rotators among females with PFP while Souza \& Powers, found a reduction of $14 \%$ in hip abductors and $17 \%$ in hip external rotators eccentric muscle strength compared to healthy matched 
controls $[16,21]$. Nevertheless, Piva et al. found no significant muscle strength differences for hip abductors and external rotators in patients with PFP compared to healthy age/gender-matched controls; however, Baldon et al. reported significantly reduced strength for eccentric hip abductors, but not for hip external rotators among females with PFP to healthy matched controls [22, 23].

The weak hip lateral rotators cause unrestricted internal rotation of the femur about the tibia, enhancing misalignment at the knee joint that in turn leads to a biomechanical imbalance between the hip extensors and lateral rotators, that overloads the retinaculum and subchondral bone and subsequently potentiate patellofemoral pain and knee dysfunction [21]. Nevertheless, Earl et al. opined that strong hip muscles (abductors and external rotators) reverses these effects over the knee joint [3].

Ireland et al. and Souza \& Powers noted more weakness in hip external rotators compared to hip abductors in patients with PFP[16] [21]. Ferber et al. found that in patients with PPS, the three weeks of isolated hip abductors strengthening not only reduces patellofemoral pain but also increases gait-related knee-joint stability [9]. Two recent randomised controlled trials found that isolated strengthening of hip abductors and external rotators effectively relieves pain and improvise knee function in females [4, 17]. The available pieces of evidence for PFP considered exercises to strengthen the hip muscles that reduces pain and enhances long-term knee function $[3,4,6,17,24]$.

\section{Outcome Measures of Pain, Knee Function and Health Status in PFP:}

The available studies used self-reported Kujala Anterior Knee Pain Scale (AKPS), Visual Analogue Pain (VAS) scale, 11-point Numerical Pain Rating Scale (NPRS) and Pain Severity Scale (PSS) as an outcome measure to document patellofemoral pain in patients with PFP receiving therapeutic interventions $[14,25,26]$.

The knee functions for patellofemoral pain were assessed using the Lower Extremity Functional Scale (LEFS), Tegner Activity Scale (TAS), Lysholm Knee Scoring Scale (LKSC)/ Tegner Lysholm Knee Scoring Scale (TLKSS), Knee Outcome Survey-Activities of Daily Living Scale (KOS$\mathrm{ADL}$ ) and Functional Index Questionnaire (FIQ) [26-30].

Though, the Western Ontario and McMaster Universities Osteoarthritis Index (WOMAC) is tailored to examine the functional status of osteoarthritis, is also been used to measure health status for patients with patellofemoral pain [because patients with osteoarthritis often present with anterior knee pain which is similar to patellofemoral pain] [25].

Since, systematic reviews evaluating the effect of hip abductors and lateral rotators strengthening for patellofemoral pain, knee function and quality of life in patients with PFP are extremely limited, even though, evidence indicating the presence of weak hip abductors and external rotators. Primarily this study systematically reviews and Meta-analyses the best-published evidence on the therapeutic value of strengthening hip abductors and lateral rotators muscles for the treatment of PFP. This is being guided by the presumptive hypothesis that strengthening hip muscles stabilises the patellofemoral joint, relieves pain and enhances knee functions.

\section{Methodology}

\section{Justification of the Systematic Review Approach}

Systematic reviews and meta-analyses are important methodologies for the qualitative and quantitative synthesis of published evidence. Shreds of evidence presented in systematic reviews are key for continuous quality and safety improvements in evidence-based clinical practice and therefore, useful for both clinicians and healthcare policymakers. The present review study used Centre for Reviews and Dissemination (CRD) guidance for undertaking reviews in health interventions to assess the value of hip muscles strengthening as therapeutic interventions in patellofemoral pain and knee function in patients with PFP [31]. Additionally, the Preferred Reporting Items for Systematic Reviews and MetaAnalyses (PRISMA) statement, recommended in CRD's guidance is used in literature searches to minimise biases in article selection and reporting [32]. The review has been registered with Open Science framework with reference doi: 10.17605/OSF.IO/CWZ8V

\section{Electronic bibliographic database searches}

The controlled clinical trials (randomised and non-randomised), controlled comparative studies and cohort studies ((prospective and retrospective) published in the last 25 years (January 1994 to September 2019) in English language journals were performed across five electronic databases [Medical Literature Analysis and Retrieval System Online (Medline); Excerpta Medica Database (EMBASE); Clinical Index of Nursing and Allied Health Literature (CINAHL); Physiotherapy Evidence Database (PEDro) and The Cochrane Central Register of Controlled Trials (CENTRAL)]. Appropriate combinations of Medical Subject Headings (MeSH) or CINAHL headings with keywords (Table 1) using Boolean Operators (AND, OR \& NOT) along with PICOS (target population, intervention, comparator, outcomes and study design) were used [33].

Additional electronic searches are done in the Meta register of Controlled Trials (mRCT) via the Current Controlled Trials (CCT) database to locate ongoing RCTs with potentially relevant data useful for the present systematic review. The potentially relevant clinical controlled trials and cohort studies (otherwise not indexed in any of the five electronic bibliographic databases and mRCT), electronic searches were supplemented by

Page $3 / 30$ 
searching unpublished papers from the OpenGrey (formerly SIGLE) database. The literature searches were additionally supplemented with manual bibliographic searches of relevant systematic reviews, editorials and thesis reports published by the digital libraries of the University of Manchester, University of Central Lancashire and Australian Digital Thesis programmes including ProQuest. Authors of potentially relevant unpublished reports were contacted by e-mails seeking clarification of their respective studies with the possibility of inclusion in the present review.

\section{Study Selection}

The study selection performed by the PRISMA flow chart where returned hits for each electronic bibliographic database were screened initially based on title and abstracts. The number of potentially relevant articles were noted and citations imported into Endnote citation manager (EndNote X7), and full-text articles retrieved for further eligibility screening. Studies were included based on the following criteria:

\section{Inclusion criteria}

1. Studies that enrolled adolescents ( $\geq 14$ to $\leq 19$ years) and/or adults ( $\geq 50$ years);

2. Studies involving patients with the confirmed clinical diagnosis of patellofemoral pain presented with anterior or retro patellar knee pain during physical activities i.e. running, climbing staircase, squatting, hopping, and kneeling or prolonged sitting;

3. Studies involving patients diagnosed with patellofemoral pain without underlying knee pathologies (e.g. Osteoarthritis), previous knee trauma or surgery;

4. Only controlled clinical trials (RCTs, Non-RCTs, and comparative studies) and cohort studies assessing the effect of hip abductors and/or external rotators strengthening on pain and functional outcomes of patients with a confirmed diagnosis of patellofemoral pain;

5. Studies published as books, chapters or conference abstracts or interim results in the mRCT database provided that authors were contacted successfully;

6. Studies comparing strengthening of hip abductors and/or external rotators muscles with standard quadriceps strengthening or no exercises;

7. Studies where the intervention group received hip muscles strengthening exercises coupled with quadriceps strengthening provided that the comparator group received only the quadriceps strengthening protocol;

8. Studies measuring pain by VAS, AKPS, 11-point NPRS, PSS, and functional outcomes examined on TAS, LKSS, FIQ, TLKSS LEFS, PFJES, or WOMAC instruments;

9. Studies published in English only were included for the review.

\section{Exclusion criteria}

1. Studies that were not quantitative such as reviews, editorials, commentaries, which merely reviewed the physiotherapeutic benefits of hip muscles strengthening to patients with patellofemoral pain;

2. Studies published more than 20 years ago;

3. Studies that recruited PFP patients with other underlying knee pathologies such as knee osteoarthritis, knee cartilaginous injuries, meniscal tears or knee surgery;

4. Studies that included the non-exercise co-interventions such as electro-muscular stimulation (electrotherapy), patella taping, and orthotics;

5. Studies reported neither patient pain nor functions.

\section{Critical Appraisal of Methodological Quality}

The McMaster Critical Review Form for Quantitative Studies applied to examine the methodological quality of all selected studies for study's objectives, literature survey, study design, sample population, intervention, outcome measures, results, significance, limitations, and conclusions (Table 2) [14]. Knowing that biases are the main threats to the internal and external validity of RCTs, quality appraisal of RCTs performed using The Cochrane Collaboration's 'Risk of bias' tool tailored specifically for RCTs [34]. The risk of patient selection bias was examined for the selected RCTs for the sufficiency of random sequence generation and concealment allocation to interventional and control groups. This helped to determine the comparability of the study groups at baseline. The risk of performance bias was evaluated based on measures (such as single blinding or double-blinding) employed to ensure study participants and personnel are blinded to interventions and outcomes. The risk of detection bias was assessed to know if the assessors were adequately blinded to patient group allocation. The risk of attrition bias and the risk of incorporation bias examined based on the rate and pattern of the dropout of participants, handling of incomplete outcome data and the indications of intention-to-treat (ITT) analysis. Finally, the risk of reporting bias evaluated based on the possibility of selective outcome reporting. The reproducibility of exercise therapies prescribed, confounding/modifying effects of co-interventions and the levels of supervision and patient compliance to the prescribed physiotherapy during the trial were also evaluated across the RCTs studies.

\section{Data Extraction and Qualitative Synthesis}


Data on effect measures were extracted for baseline patellofemoral pain levels, hip exercise interventions, including the comparator treatment, quantitative assessment of patient outcomes for patellofemoral pain and functions, follow-up duration and post-intervention practices during the follow-up periods. Statistical results (mean differences from baseline and effect measures $P$ value at $95 \%$ confidence interval) were taken from the evidence tables for interventional studies (separately for controlled clinical trials and cohort studies).

\section{Quantitative Synthesis (Meta-Analysis)}

Using MedCalc software (Version 14.10.2, MedCalc Software Ltd), data from RCTs that provided the mean difference of pain or knee function between the intervention and the comparator groups were pooled by random or fixed-effect models to obtain standardised mean differences. Separate forest plots were generated for pain and knee function outcome.

\section{Results}

The primary electronic searches in the five bibliographic databases using the PICOS search strategy returned 114 potentially relevant citations. Through careful screening for duplicates based on titles and authors, 50 citations were excluded. The 43 articles were excluded after careful screening of titles and abstracts from the remaining 64 articles because they were not irrelevant. The full texts of the remaining 21 articles were evaluated rigorously for eligibility based on the inclusion and exclusion criteria, and through this process, 10 studies were excluded because of the following reasons;

1. Six articles excluded because they involved patients with knee osteoarthritis or mixed participants with PFP and osteoarthritis,

2. Two studies excluded because they focused on hip/quadriceps muscle strengths as the only outcome measure after interventions without assessing pain or functional outcomes,

3. One study appeared relevant, but lacked the description of exercise interventions administered,

4. Lastly, one study contained duplicate experimental data from another included original study.

Three potentially relevant studies were identified through manual bibliographic hand searches of three recent systematic reviews [14,35,36]. The complete process yielded 14 studies. Among these, 10 were controlled clinical trials (CCTs), and 3 were cohort studies while 1 was a case series $[3,4,6,9,17,24,37-44]$. The 3 cohort studies met the inclusion criteria for qualitative synthesis. Nine controlled clinical trials were true randomised controlled trials (RCTs) presenting data suitable for quantitative synthesis (meta-analysis) $[4,6,17,24,37-39,41,42]$. The literature search strategy and article selection process are summarised in the PRISMA flow chart (Fig. 1) [32].

\section{Controlled Clinical Trials}

A total of 383 participants from the 10 CCTs received either hip-strengthening exercises $(\mathrm{N}=74)$ or quadriceps strengthening exercises ( $\mathrm{N}=157)$ or hip/quadriceps strengthening exercises $(\mathrm{N}=108)$ or no exercise $(\mathrm{N}=44)$ (Table 2). All CCTs involved true randomization of participants except one, where participants were allocated to their respective groups alternately in a consecutive manner [40].

\section{Intervention Protocol:}

In all CCTs, the hip muscles strengthening protocol focused on hip abductors and lateral rotators. The hip exercise protocol included hip abduction against an elastic band while standing, or with weights in side-lying position coupled with hip lateral rotation against an elastic band while seated and hip extension; quadriceps strengthening involved closed kinetic chain exercise or seated knee extension, leg press, squatting and stretching of hamstrings and quadriceps; and, hip-quadriceps strengthening involved combination of the hip-quadriceps protocol. The duration of intervention ranged from 3- 8 weeks, while the frequency of therapy sessions ranged from 2-4 per week (Table 3).

\section{Outcome measures}

All CCTs examined both pain and functional outcomes except one, which assessed only pain [41]. The pain was commonly evaluated using 10cm VAS by all CCTs except two, which used the 11-point NPRS [4,24]. The pain was evaluated during ascending and descending stairs [4,24,41], squatting, usual pain [41], and worst knee pain in the previous week [6,17,39-42]. Functional outcomes were assessed using LEFS [4,6,24,38], AKPS [4,6,24,39], PFJES [37], TLKSS [42] and WOMAC [17,40].

\section{Follow-up duration}

Post-intervention measures were immediately carried out at the end of the intervention period in all studies. However, the post- interventional follow-up period ranged from one to twelve months (Table 4).

\section{Critical appraisal}


Methodological quality assessment of the 10 CCTs based on the Cochrane Collaboration's 'Risk of bias' tool tailored for RCTs is detailed in Table 5 \& 6 below [34].

\section{Cohort and Case Series Studies}

The three cohort studies had 88 participants [PFP $(n=64)$; healthy controls $(n=24)$ ]. The one case series involved 19 participants with PFP.

Intervention Protocol:

In one cohort study, the experimental group given hip muscles exercise protocol (strengthening of hip abductors and external rotators), and the control group received knee exercises. The other two cohort studies subjects received quadriceps- strengthening [43,44]. The duration of intervention ranged between three to six weeks. The case series participants completed an eight-week exercise programme focusing on hip muscles strengthening and improving dynamic misalignment (Table 7).

\section{Meta-analysis (pooled effect size)}

The meta-analysis was done to determine the additional effect of hip muscles strengthening as adjunctive therapy to the standard quadriceps strengthening for PFP and knee function.

\section{A. The comparative effect size of Hip versus Quadriceps strengthening on pain and function}

Two RCTs [6,38] and one comparative control trial [40] provided data that compared the effect of the isolated strengthening of hip muscles (hip abductors and lateral rotators) versus the standard quadriceps strengthening on PFP and knee function. A total of 100 participants were randomly assigned to receive either hip $(n=50)$ or quadriceps $(n=50)$ strengthening protocols. The standardised mean difference (SMD) of PFP and functional outcomes after intervention with $95 \% \mathrm{Cl}$ under both fixed and random effects models favoured hip muscles strengthening over quadriceps strengthening ( $p<0.001)$ (Fig. 2 and 3 ).

\section{B. Surplus effect of hip-quad versus quadriceps strengthening on pain and function}

Five RCTs contributed data assessing the surplus effect of hip muscles strengthening coupled with quadriceps strengthening compared to the standard quadriceps strengthening alone on PFP and knee function $[4,24,39,41,42]$. For both the group (hip-quad and quadriceps alone), 16 data sets were collected from a total of 98 participants. The pooled effects of results are presented in forest plots Fig. 4 and 5 as cumulative SMD with $95 \% \mathrm{Cl}$, under both fixed and random-effects models.

\section{Discussion}

Two recent systematic reviews have demonstrated that proximal exercises targeting quadriceps and hip muscles strengthening were effective in relieving pain and improving knee function in patients with PFP, both the short- and long-term [14,36]. However, this systematic review was important to delineate the effect of the isolated strengthening of hip abductors and lateral rotators on pain and knee function in patients with PFP compared to non-exercise interventions and to identify if hip muscles strengthening is superior over the quadriceps strengthening alone among them.

\section{A. Quality of the Summarised Evidence}

The methodological quality of the fourteen studies except five i.e. $[6,9,37,43,44]$ included in the present review is excellent because it fulfilled 14 of the 16-item McMaster critical review criteria. The common methodological issue observed in the majority of the selected studies was lack of sample size justification (sample size not determined or not achieved) $[6,17,37,39,40,43]$. All studies with sample power inadequacy issue, achieved results with statistical significance, suggesting that the measured pain and functional outcomes reflect the comparative effect of the interventions. However, subject contamination in Dolak et al. was evident because hip and quadriceps groups were combined as one to receive functional strengthening exercises (as co-interventions for the last four weeks of the intervention) [6]. Such subject contamination might have caused patient bias for their pain and functional outcomes, especially if they know the intervention of their cohorts in the opposite arm of the study [45].

This risk of bias is a critical methodological issue in RCTs and warranted supplementary quality appraisal of all RCTs on the Cochrane Collaboration's 'Risk of bias tool [34] to highlight methodological flaws (indicative of 'Risk of bias' threatening interval consistency) (Table 6). All RCTs except two recruited participants with a confirmed diagnosis of PFP $[17,40]$. However, these studies were included because they enrolled patients presented with anterior keen pain based on symptoms matching the inclusion criteria of the remaining RCTs, which recruited patients with a confirmed diagnosis of PFP. Here, 383 participants from all RCTs presented with anterior knee pain associated with prolonged sitting, climbing stairs and descending stairs in the absence of signs/symptoms of meniscal or other intra-articular pathological conditions, or history of

Page 6/30 
other knee pathologies, surgeries and injuries. These are classical symptoms for the diagnosis of PFP [14,36]. However, these symptoms may be indicative of knee osteoarthritis, but it may not be so likely because patients enrolled in RCTs were not older than 50 years of age, and therefore not likely to present with ageing-associated PFP [46].

Four studies included the mixed population of both adults and adolescents aged 17 to 50 years $[6,38,39,41]$. Since adolescents are physically active, therefore, at risk of PFP, hence, the inclusion of this age group [46]. To minimise the possibility of recruiting participants with underlying knee pathologies i.e. knee osteoarthritis, no studies recruited patients with PFP who were older than 50 years of age [46]. The four studies examined only female participants, therefore, the outcome may only be generalised for the female patients with PFP, but not for the males $[4,6,24,38]$. The three studies [39,41,42], included both males and female participants (proportion of females was higher than males), indicative of females being the greater risk of PFP than males [6]. This may be attributed to the lower hip muscle mass in females compared to males [47], therefore, females exhibiting lower hip muscle strength than males $[47,48]$.

The symptom duration is a direct measure of severity of PFP that has a significant influence on therapeutic outcome [49]. Therefore, patients with early diagnosis of PFP likely to respond well to therapy compared to those with late diagnosis [20]. Thus, symptom duration is a key confounding variable that needs to be adjusted via the subject's stratification. In this systematic review, the mean duration of symptoms of participants with PFP in eight studies ranged from 17 to 21 months. However, six studies [17,37-41] did not report the mean duration (months) of PFP symptoms. None of the studies performed the subject's stratification for the PFP severity and symptom duration. This might have positively skewed pain and functional outcomes in patients with a shorter mean duration of symptoms [20]. Additionally, the subject's characteristics were barely explained in three studies $[38,40,41]$ and also not detailed in one study [37]. These findings undermine the quality of the summarised shreds of evidence.

Supervised therapeutic exercises enhance participant's compliance because unsupervised participants may refrain from pain-provoking exercises $[20,50]$. Two previous RCTs had reported that supervised exercises for PFP result in less pain and better knee function at short- and long-term follow-up compared to usual care [20,50]. In the present systematic review, all studies involved exercises administered in physiotherapy facility/ rehabilitation setting under supervision by qualified physiotherapists, except two [6,41], where two-thirds of exercise sessions were selfadministered in patients homes (unsupervised), while one-third had at rehabilitation facility under supervision. It had an important bearing on patient compliance to intervention and the outcome. Even then, results were significant in these two studies suggesting that partial supervision too can yield clinically significant results.

\section{B. Isolated Hip Musculature Strengthening}

All fourteen studies demonstrated that isolated strengthening exercises of hip abductors \& lateral rotators for two to four times per week up to three to eight weeks duration is effective in relieving pain and improving knee function compared to quadriceps strengthening and non-exercise interventions. Kooiker et al. reported variations in quadriceps, hip and hip-quadriceps strengthening protocols in selected studies, and opined for the unavailability of standardized protocols for PFP [36]. The common hip exercise protocol included hip abduction against an elastic band while standing, and with weights in a side-lying position coupled with hip lateral rotation against an elastic band while seated and hip extension ( 3 sets of 10 repetitions). Conversely, quadriceps strengthening in all studies generally involved weight-bearing and non-weight-bearing exercises such as closed kinetic chain exercises, seated knee extension, leg press, squatting and stretching of hamstrings and quadriceps (3 sets of 10 repetitions).

The hip protocol generally resulted in improved pain and knee function after three to eight weeks of training, with long-term effects observed as late as twelve months post-intervention [24].Four studies evaluated comparative therapeutic value of quadriceps versus hip muscles strengthening in treating PFP $[6,37,38,40]$. One study by Khayambashi et al. reported superiority of hip muscles strengthening strategy over the quadriceps strengthening for both pain and functional improvement in PFP [40]. The remaining three studies opined that isolated hip and quadriceps strengthening strategy have comparable therapeutic value for the PFP [6,37,38]. However, a meta-analysis of the effect measures (pain and function) as measured on VAS and LEFS or WOMAC revealed that hip strengthening significantly favours over the standard quadriceps strengthening $(p<0.001)$ in PFP treatment $[6,38,40]$.

\section{Surplus Therapeutic Effect of Hip Muscles Strengthening}

Though the proximal strengthening exercises involving quadriceps and hip muscles are commonly effective in treating PFP, Kooiker et al., Peters \&Tyson opined that a combination of hip-quadriceps strategy could add the therapeutic outcome for the patients with PFP [6,14,36-38].The present systematic review included five RCTs to examine the surplus therapeutic outcome of hip-quadriceps strengthening exercises over the standard quadriceps $[4,24,39,41,42]$. All studies except one supported that hip-quadriceps strategy was superior to the standard quadriceps [42].

The findings of these five RCTs have both internal and external validity and are, therefore, acceptable. Furthermore, meta-analysed data of these five studies strongly indicated that quadriceps coupled with hip muscles strengthening has significant surplus therapeutic benefits over the

Page $7 / 30$ 
conventional quadriceps or the hip exercises in the treatment of PFP $(p<0.001)$. Therefore, a hip-quadriceps strategy should be adopted in clinical practices for pain relief and optimal functional improvements in patients with PFP.

\section{Limitations}

The summarised pieces of evidence supported by meta-analyses indicate that strengthening of hip muscles is effective in treating PFP for pain and knee function of physically active male/female adolescents and adults. However, a few but important limitations must be noted;

1. This systematic review and meta-analysis initially were intended to review a minimum of 20 studies to examine the therapeutic outcome of hip muscles strengthening versus quadriceps alone on pain and knee functions for patients with PFP. The expanded literature search yielded only 14 studies that are adequate for systematic review limits the strength and generalisability of the summarised findings over a wider population of patients with PFP.

2. Avraham et al. study (included in this review) used a non-exercise (electrotherapy) as a co-intervention that might have uni-directionally augmented the therapeutic effects [37].

3. Though the proportion of females to males is higher in all studies (included in this review), but this may not be considered as a limitation to generalisability for a wider group of patients with PFP, because it truly reflects the characteristics of patients with PFP that would be encountered in day-to-day clinical practice.

\section{Implications for routine physiotherapy practice}

The evidence from the present review has important implications in routine clinical practice for the patients with PFP:

1. Strong shreds of evidence favour hip muscles strengthening exercises for two to four times a week, up to three to four weeks, to have effective therapeutic outcome compared to standard quadriceps strengthening exercises alone in patients with PFP. This implies that therapists should consider hip muscles strengthening as standard therapeutic measures while treating patients with PFP.

2. Meta-analysis of the effect measures (both pain and function) has strongly supported that hip muscles coupled with quadriceps (hip-quad) strengthening has superior therapeutic effects compared to the individual isolated hip or quadriceps strengthening exercises. This evidence strongly implies that therapists should consider a combination of hip and quadriceps strengthening exercises for the treatment of patients with PFP. However, this may imply longer therapy sessions plus more sessions per week that may influence patient's compliance to intervention, especially if prescribed as self-efficacy [51].

3. In the present review, only one study [24]out of fourteen had followed patients up to twelve months, which was a good attempt to determine the long-term therapeutic effect of hip versus quadriceps strengthening exercises on PFP and knee function. This is indicative of evidence to be generalised only for the short-term, instead of long-term pain and functional outcomes.

\section{Future Research}

Must consider stratification of patients/results based on the symptom duration before the intervention, to eliminate the effect of time-delay modification on pain and functional outcomes following hip muscles strengthening in patients with PFP.

\section{Conclusion}

The results of this systematic review and meta-analysis indicate that isolated strengthening of hip abductors and lateral rotators has therapeutic benefits compare to quadriceps strengthening alone for the treatment of PFP. It is also clear that the hip-quadriceps strategy gives a greater therapeutic outcome than isolated quadriceps or hip muscles strengthening. Therefore, we recommend developing a hip-quadriceps exercise strategy for the treatment of PFP to encourage improved compliance, even in unsupervised patients.

\section{Abbreviations}

PFP: Patellofemoral pain; PRISMA: Preferred Reporting Items for Systematic Reviews and Meta-Analyses; CRD: Centre for Reviews and Dissemination

\section{Declarations}

Funding: No funds, grants, or other support was received for conducting this study 
Conflicts of interest/Competing interests: The authors have no financial or non-financial conflicts of interest to declare that are relevant to the content of this article

\section{Code availability: Not applicable}

\section{Authors' contributions:}

AAA: Conception and design; Literature search; Data acquisition; Data entry and analysis; Manuscript preparation.

NS: Conception and design; Defining intellectual content; Data interpretation; Manuscript editing and review

AN: Conception and design; Defining intellectual content; Data interpretation; Manuscript editing and review

SKK: Manuscript editing, review, submission

ZCO: Data interpretation and review

Ethics approval: Ethical approval was waived as human subjects were not directly contacted or included in the study.

Consent to participate: Not Applicable

Consent for publication: Authors have no objections regarding publications of study data.

\section{References}

1. Dixit S, DiFiori JP, Burton M, Mines B. Management of Patellofemoral Pain Syndrome. Am Fam Physician. 2007;75:194-202.

2. Atanda A, Ruiz D, Dodson CC, Frederick RW. Approach to the active patient with chronic anterior knee pain. Phys Sportsmed. 2012;40:41-50. https://doi.org/10.3810/psm.2012.02.1950

3. Earl JE, Hoch AZ. A proximal strengthening program improves pain, function, and biomechanics in women with patellofemoral pain syndrome. Am J Sports Med. 2011; 9:154-163. https://doi.org/10.1177/0363546510379967

4. Fukuda TY, Rossetto FM, Magalhães E, Bryk FF, Lucareli PRG, de Almeida Carvalho NA. Short-term effects of hip abductors and lateral rotators strengthening in females with patellofemoral pain syndrome: A randomized controlled clinical trial. J Orthop Sports Phys Ther. 2010; 40:736-42. https://doi.org/10.2519/jospt.2010.3246

5. Lankhorst NE, Bierma-Zeinstra SMA, van Middelkoop M. Risk factors for patellofemoral pain syndrome: A systematic review. J Orthop Sports Phys Ther. 2012; 42:81-94. https://doi.org/10.2519/jospt.2012.3803

6. Dolak KL, Silkman C, Mckeon JM, Hosey RG, Lattermann C, Uhl TL. Hip strengthening prior to functional exercises reduces pain sooner than quadriceps strengthening in females with patellofemoral pain syndrome: A randomized clinical trial. J Orthop Sports Phys Ther. 2011; 41:560-70. https://doi.org/10.2519/jospt.2011.3499

7. Sherman SL, Plackis AC, Nuelle CW. Patellofemoral anatomy and biomechanics. Clin Sports Med. 2014;33:389-401.

8. Bolgla LA, Malone TR, Umberger BR, Uhl TL. Comparison of hip and knee strength and neuromuscular activity in subjects with and without patellofemoral pain syndrome. Int J Sports Phys Ther. 2011; 6:285-96.

9. Ferber R, Kendall KD, Farr L. Changes in knee biomechanics after a hip-abductor strengthening protocol for runners with patellofemoral pain syndrome. J Athl Train. 2011; 6:142-9. https://doi.org/10.4085/1062-6050-46.2.142

10. Mascal CL, Landel R, Powers C. Management of Patellofemoral Pain Targeting Hip, Pelvis, and Trunk Muscle Function: 2 Case Reports. J Orthop Sports Phys Ther. 2003;33:647-60. https://doi.org/10.2519/jospt.2003.33.11.647

11. Chiu JKW, Wong YM, Yung PSH, Ng GYF.The effects of quadriceps strengthening on pain, function, and patellofemoral joint contact area in persons with patellofemoral pain. Am J Phys Med Rehabil. 2012;91:98-106. https://doi.org/10.1097/PHM.0b013e318228c505

12. Eapen C, Nayak CD, Zulfeequer CP. Effect of eccentric isotonic quadriceps muscle exercises on patellofemoral pain syndrome: An exploratory pilot study. Asian J Sports Med.2011;2:227-34. https://doi.org/10.5812/asjsm.34747

13. Kaya D, Doral MN, Callaghan M. How can we strengthen the quadriceps femoris in patients with patellofemoral pain syndrome? Muscles Ligaments Tendons J. 2012;2:25-32. https://www.ncbi.nlm.nih.gov/pmc/articles/PMC3666499/

14. Peters JSJ, Tyson NL. Proximal exercises are effective in treating patellofemoral pain syndrome: a systematic review. Int J Sports Phys Ther. 2013;8:689-700. https://pubmed.ncbi.nlm.nih.gov/22402677/

15. Flack NAMS, Nicholson HD, Woodley SJ. The anatomy of the hip abductor muscles. Clin Anat. 2014; 27:241-53.

https://doi.org/10.1002/ca.22248

Page 9/30 
16. Ireland ML, Willson JD, Ballantyne BT, Davis IMC. Hip Strength in Females with and without Patellofemoral Pain. J Orthop Sports Phys Ther. 2003;33:671-6. https://doi.org/10.2519/jospt.2003.33.11.671

17. Khayambashi K, Mohammadkhani Z, Ghaznavi K, Lyle MA, Powers CM. The effects of isolated hip abductor and external rotator muscle strengthening on pain, health status, and hip strength in females with patellofemoral pain: A randomized controlled trial. $\mathrm{J}$ Orthop Sports Phys Ther. 2012; 42:22-9. https://doi.org/10.2519/jospt.2012.3704

18. Robinson RL, Nee RJ. Analysis of hip strength in females seeking physical therapy treatment for unilateral patellofemoral pain syndrome. J Orthop Sports Phys Ther. 2007;37:232-8. https://doi.org/10.2519/jospt.2007.2439

19. Bell DR, Oates DC, Clark MA, Padua DA. Two- and 3-dimensional knee valgus are reduced after an exercise intervention in young adults with demonstrable valgus during squatting. J Athl Train. 2013; 48:442-9. https://doi.org/10.4085/1062-6050-48.3.16

20. Prins MR, van der Wurff P. Females with patellofemoral pain syndrome have weak hip muscles: a systematic review. Aust J Physiother. 2009; 55:9-15. https://doi.org/10.1016/S0004-9514(09)70055-8

21. Souza RB, Powers CM. Differences in hip kinematics, muscle strength, and muscle activation between subjects with and without patellofemoral pain. J Orthop Sports Phys Ther. 2009;39:12-9. https://doi.org/10.2519/jospt.2009.2885

22. Baldon R de M, Nakagawa TH, Muniz TB, Amorim CF, Maciel CD, Serrão FV. Eccentric hip muscle function in females with and without patellofemoral pain syndrome. J Athl Train. 2009; 44:490-6. https://doi.org/10.4085/1062-6050-44.5.490

23. Piva SR, Goodnite EA, Childs JD. Strength around the hip and flexibility of soft tissues in individuals with and without patellofemoral pain syndrome. J Orthop Sports Phys Ther. 2005;35:793-801. https://doi.org/10.2519/jospt.2005.35.12.793

24. Fukuda TY, Melo WP, Zaffalon BM, Rossetto FM, Magalhães E, Bryk FF et al. Hip posterolateral musculature strengthening in sedentary women with patellofemoral pain syndrome: A randomized controlled clinical trial with 1-year follow-up. J Orthop Sports Phys Ther.2012;42:823-30. https://doi.org/10.2519/jospt.2012.4184

25. Collins NJ, Misra D, Felson DT, Crossley KM, Roos EM. Measures of knee function: International Knee Documentation Committee (IKDC) Subjective Knee Evaluation Form, Knee Injury and Osteoarthritis Outcome Score (KOOS), Knee Injury and Osteoarthritis Outcome Score Physical Function Short Form (KOOS-PS), Knee Outcome Survey Activities of Daily Living Scale (KOS-ADL), Lysholm Knee Scoring Scale, Oxford Knee Score (OKS), Western Ontario and McMaster Universities Osteoarthritis Index (WOMAC), Activity Rating Scale (ARS), and Tegner Activity Score (TAS). Arthritis Care Res.2011;63:208-28. https://doi.org/10.1002/acr.20632

26. Da Cunha RA, Pena Costa LO, Hespanhol Junior LC, Pires RS, Kujala UM, Lopes AD.Translation, cross-cultural adaptation, and clinimetric testing of instruments used to assess patients with patellofemoral pain syndrome in the Brazilian population. J Orthop Sports Phys Ther.2013;43:332-9. https://doi.org/10.2519/jospt.2013.4228

27. Briggs KK, Kocher MS, Rodkey WG, Steadman JR. Reliability, validity, and responsiveness of the Lysholm knee score and tegner activity scale for patients with meniscal injury of the knee. J Bone Joint Surg - Series A. 2006;88:698-705. https://doi.org/10.2106/JBJS.E.00339

28. Piva SR, Gil AB, Moore CG, Fitzgerald GK. Responsiveness of the activities of daily living scale of the knee outcome survey and numeric pain rating scale in patients with patellofemoral pain. J Rehabil Med.2009;41:129-35. https://doi.org/10.2340/16501977-0295

29. Cruz-Díaz D, Lomas-Vega R, Osuna-Pérez MC, Hita-Contreras F, Fernández ÁD, Martínez-Amat A.The Spanish lower extremity functional scale: A reliable, valid and responsive questionnaire to assess musculoskeletal disorders in the lower extremity. Disabil Rehabil.2014;36:2005-11. https://doi.org/10.3109/09638288.2014.890673

30. Williams VJ, Piva SR, Irrgang JJ, Crossley C, Fitzgerald GK.Comparison of reliability and responsiveness of patient-reported clinical outcome measures in knee osteoarthritis rehabilitation. J Orthop Sports Phys Ther.2012;42:716-23.

31. Tacconelli E.Systematic reviews: CRD's guidance for undertaking reviews in health care. Lancet Infect Dis.2010;10:226. https://doi.org/10.1016/s1473-3099(10)70065-7

32. Liberati A, Altman DG, Tetzlaff J, Mulrow C, Gøtzsche PC, loannidis JPA et al.The PRISMA statement for reporting systematic reviews and meta-analyses of studies that evaluate health care interventions: Explanation and elaboration. PLoS Med.2009 6:e1000100.

https://pure.qub.ac.uk/en/publications/the-prisma-statement-for-reporting-systematic-reviews-and-meta-an

33. Sayers A.Tips and tricks in performing a systemic review. Br J Gen Pract.2008;58:136.

34. Higgins JPT, Altman DG, Gøtzsche PC, Jüni P, Moher D, Oxman AD et al. The Cochrane Collaboration's tool for assessing risk of bias in randomised trials. BMJ (Online). 2011;343:1-9. https://doi.org/10.1136/bmj.d5928

35. Frye JL, Ramey LN, Hart JM. The Effects of Exercise on Decreasing Pain and Increasing Function in Patients With Patellofemoral Pain Syndrome: A Systematic Review. Sports Health.2012;4:205-10. https://doi.org/10.1177/1941738112441915

36. Kooiker L, van de Port IGL, Weir A, Moen MH. Effects of physical therapist-guided quadriceps-strengthening exercises for the treatment of patellofemoral pain syndrome: A systematic review. J Orthop Sports Phys Ther.2014;44:391-402.

37. Avraham F, Aviv S, Ya'akobi P, Faran H, Fisher Z, Goldman Y et al.The efficacy of treatment of different intervention programs for patellofemoral pain syndrome - A single blinded randomized clinical trial. Pilot study. Scientific World Journal. 2007;7:1256-62. https://doi.org/10.1100/tsw.2007.167

Page $10 / 30$ 
38. de Marche Baldon R, Serrão FV, Silva RS, Piva SR.Effects of functional stabilization training on pain, function, and lower extremity biomechanics in women with patellofemoral pain: A randomized clinical trial. J Orthop Sports Phys Ther.2014;44:240-51.

https://doi.org/10.2519/jospt.2014.4940

39. Ismail MM, Gamaleldein MH, Hassa KA. Closed Kinetic Chain exercises with or without additional hip strengthening exercises in management of Patellofemoral pain syndrome: A randomized controlled trial. Eur J Phys Rehabil Med. 2013;49:687-98.

40. Khayambashi K, Fallah A, Movahedi A, Bagwell J, Powers C.Posterolateral hip muscle strengthening versus quadriceps strengthening for patellofemoral pain: A comparative control trial. Arch Phys Med Rehabil. 2014; 95:900-7. https://doi.org/10.1016/j.apmr.2013.12.022

41. Nakagawa TH, Muniz TB, Baldon R de M, Dias Maciel C, de Menezes Reiff RB, Serrão FV.The effect of additional strengthening of hip abductor and lateral rotator muscles in patellofemoral pain syndrome: A randomized controlled pilot study. Clin Rehabil.2008;22:1051-60. https://doi.org/10.1177/0269215508095357

42. Song CY, Lin YF, Wei TC, Lin DH, Yen TY, Jan MH. Surplus value of hip adduction in leg-press exercise in patients with patellofemoral pain syndrome: A randomized controlled trial. Phys Ther.2009;89:409-18. https://doi.org/10.2522/ptj.20080195

43. Boling MC, Bolgla LA, Mattacola CG, UhI TL, Hosey RG. Outcomes of a Weight-Bearing Rehabilitation Program for Patients Diagnosed With Patellofemoral Pain Syndrome. Arch Phys Med Rehabil.2006;87:1428-35. https://doi.org/10.1016/j.apmr.2006.07.264

44. Tyler TF, Nicholas SJ, Mullaney MJ, McHugh MP.The role of hip muscle function in the treatment of patellofemoral pain syndrome. Am J Sports Med. 2006;34:630-6. https://doi.org/10.1177/0363546505281808

45. Singal AG, Higgins PDR, Waljee AK. A primer on effectiveness and efficacy trials. Clin Transl Gastroenterol. 2014;5:1-4. https://doi.org/10.1038/ctg.2013.13

46. Calmbach WL, Hutchens M. Evaluation of patients presenting with knee pain: Part II. Differential diagnosis. Am Fam Physician.2003;68:91722.

47. Shultz SJ, Dudley WN, Kong Y. Identifying multiplanar knee laxity profiles and associated physical characteristics. J Athl Train. 2012;47:15969. https://doi.org/10.4085/1062-6050-47.2.159

48. Nadler SF, Malanga GA, DePrince M, Stitik TP, Feinberg JH. The relationship between lower extremity injury, low back pain, and hip muscle strength in male and female collegiate athletes. Clin J Sport Med.2000;10:89-97. https://doi.org/10.1097/00042752-200004000-00002

49. Näslund JE, Odenbring S, Näslund UB, Lundeberg T. Diffusely increased bone scintigraphic uptake in patellofemoral pain syndrome. Br J Sports Med.2005;39:162-5. https://doi.org/10.1136/bjsm.2004.012336

50. Hart L.Supervised exercise versus usual care for patellofemoral pain syndrome. Clin J Sport Med.2010;20:133-4. https://pubmed.ncbi.nlm.nih.gov/20215901/

51. Campbell R, Evans M, Tucker M, Quilty B, Dieppe P, Donovan JL.Why don't patients do their exercises? Understanding non-compliance with physiotherapy in patients with osteoarthritis of the knee. J. Epidemiol. Community Health.2001;55:132-8.

https://doi.org/10.1136/jech.55.2.132

\section{Tables}

Table 1: Medical Subject Headings (MeSH) terms and keywords for PICOS search strategy 


\begin{tabular}{|c|c|c|}
\hline & Common MeSH terms & Text words (keywords) \\
\hline Population & $\begin{array}{l}\text { Humans, adult, female, male } \\
\text { adolescents and young adults }\end{array}$ & “Patellofemoral pain”, “Anterior knee pain”, “Chondromalacia patella” \\
\hline Intervention & $\begin{array}{l}\text { Exercise Therapy, Exercise } \\
\text { Therapy/methods, Physical Therapy } \\
\text { Modalities, Patellofemoral Pain } \\
\text { Syndrome/rehabilitation, Hip } \\
\text { physiology, Knee Joint } \\
\text { physiopathology, Combined Modality } \\
\text { Therapy }\end{array}$ & $\begin{array}{l}\text { Exercise-based interventions targeting hip muscles strengthening "hip exercises" or } \\
\text { "hip-strengthening exercises." }\end{array}$ \\
\hline Comparator & $\begin{array}{l}\text { Quadriceps Muscle physiology/ physio- } \\
\text { pathology, }\end{array}$ & $\begin{array}{l}\text { Exercise-based interventions targeting knee muscles strengthening or stretching } \\
\text { (quadriceps protocol): "quadriceps strengthening exercise”, "knee strengthening } \\
\text { exercise", "Knee stretching exercises," and "knee stabilizing exercises" OR no } \\
\text { treatment }\end{array}$ \\
\hline \multirow[t]{3}{*}{ Outcomes } & $\begin{array}{l}\text { Treatment Outcome, Pain Measurement, } \\
\text { Recovery of Function }\end{array}$ & $\begin{array}{l}\text { Anterior knee pain: "pain measurement", "The Kujala Anterior Knee Pain } \\
\text { Scale"(AKPS),"The Visual Analogue Pain Scale" (VAS),11-Point Numerical Pain } \\
\text { Rating Scale"(NPRS), "self-reported pain", "Pain Severity Scale"(PSS). }\end{array}$ \\
\hline & & $\begin{array}{l}\text { Function: "knee function", "functional outcome questionnaire for the knee pain," } \\
\text { "Lower Extremity Functional Scale" (LEFS), "Tegner Activity Scale"(TAS), "Lysholm } \\
\text { Knee Scoring Scale" (LKSS), "Tegner Lysholm Knee Scoring Scale" (TLKSS), "Knee } \\
\text { Outcome Survey-Activities of Daily Living Scale" and "Functional Index } \\
\text { Questionnaire" (FIQ), "Patello-femoral joint evaluation scale" (PFJES) }\end{array}$ \\
\hline & & $\begin{array}{l}\text { Health status: “Western Ontario and McMaster Universities Osteoarthritis } \\
\text { Index"(WOMAC) }\end{array}$ \\
\hline $\begin{array}{l}\text { Study types } \\
\text { (design) }\end{array}$ & \multicolumn{2}{|c|}{$\begin{array}{l}\text { Publication types: controlled clinical trial, randomised controlled trial, non-randomised controlled trial, controlled comparative } \\
\text { study, comparative study, cohort studies, follow-up studies, observational studies (prospective study, retrospective study, case } \\
\text { series), systematic reviews }\end{array}$} \\
\hline
\end{tabular}

Table 2: Methodological quality of selected studies rated on McMaster critical review form 


\begin{tabular}{|c|c|c|c|c|c|c|c|c|c|c|c|c|c|c|c|c|c|c|c|}
\hline Author (s) & $\begin{array}{l}\text { Study } \\
\text { design }\end{array}$ & $\begin{array}{l}\text { Level of } \\
\text { evidence }\end{array}$ & 1 & 2 & 3 & 4 & 5 & 6 & 7 & 8 & 9 & 10 & 11 & 12 & 13 & 14 & 15 & 16 & $\begin{array}{l}\text { Score } \\
/ 16\end{array}$ \\
\hline $\begin{array}{l}\text { Avraham et } \\
\text { al., } 2007\end{array}$ & RCT & Level 2b & $\checkmark$ & $\checkmark$ & $\checkmark$ & $\checkmark$ & $x$ & $x$ & $x$ & $x$ & $\checkmark$ & $\checkmark$ & $x$ & $\checkmark$ & $\checkmark$ & $\checkmark$ & $\checkmark$ & $\checkmark$ & $10 / 16$ \\
\hline $\begin{array}{l}\text { Baldon et al., } \\
2014\end{array}$ & RCT & level 1b & $\checkmark$ & $\checkmark$ & $\checkmark$ & $\checkmark$ & $\checkmark$ & $\checkmark$ & $\checkmark$ & $\checkmark$ & $\checkmark$ & $\checkmark$ & $\checkmark$ & $\checkmark$ & $\checkmark$ & $\checkmark$ & $\checkmark$ & $\checkmark$ & $15 / 16$ \\
\hline $\begin{array}{l}\text { Dolak et al., } \\
2011\end{array}$ & RCT & level 2b & $\checkmark$ & $\checkmark$ & $\checkmark$ & $\checkmark$ & $x$ & $\checkmark$ & $\checkmark$ & $x$ & $\checkmark$ & $x$ & $x$ & $\checkmark$ & $\checkmark$ & $\checkmark$ & $\checkmark$ & $\checkmark$ & $12 / 16$ \\
\hline $\begin{array}{l}\text { Fukuda et al., } \\
2010\end{array}$ & RCT & level 1b & $\checkmark$ & $\checkmark$ & $\checkmark$ & $\checkmark$ & $\checkmark$ & $\checkmark$ & $\checkmark$ & $\checkmark$ & $\checkmark$ & $\checkmark$ & $\checkmark$ & $\checkmark$ & $\checkmark$ & $\checkmark$ & $\checkmark$ & $\checkmark$ & $16 / 16$ \\
\hline $\begin{array}{l}\text { Fukuda et al., } \\
2012\end{array}$ & $\mathrm{RCT}$ & level 1b & $\checkmark$ & $\checkmark$ & $\checkmark$ & $\checkmark$ & $\checkmark$ & $\checkmark$ & $\checkmark$ & $\checkmark$ & $\checkmark$ & $\checkmark$ & $\checkmark$ & $\checkmark$ & $\checkmark$ & $\checkmark$ & $\checkmark$ & $\checkmark$ & $16 / 16$ \\
\hline $\begin{array}{l}\text { Ismail et al., } \\
2013\end{array}$ & RCT & Level 2b & $\checkmark$ & $\checkmark$ & $\checkmark$ & $\checkmark$ & $x$ & $\checkmark$ & $\checkmark$ & $\checkmark$ & $\checkmark$ & $\checkmark$ & $\checkmark$ & $\checkmark$ & $\checkmark$ & $\checkmark$ & $\checkmark$ & $\checkmark$ & $14 / 16$ \\
\hline $\begin{array}{l}\text { Khayambashi } \\
\text { et al. } 2014\end{array}$ & ССТ & Level 2b & $\checkmark$ & $\checkmark$ & $\checkmark$ & $\checkmark$ & $x$ & $\checkmark$ & $\checkmark$ & $\checkmark$ & $\checkmark$ & $\checkmark$ & $\checkmark$ & $\checkmark$ & $\checkmark$ & $\checkmark$ & $\checkmark$ & $\checkmark$ & $14 / 16$ \\
\hline $\begin{array}{l}\text { Khayambashi } \\
\text { et al. } 2012\end{array}$ & RCT & Level 2b & $\checkmark$ & $\checkmark$ & $\checkmark$ & $\checkmark$ & $x$ & $\checkmark$ & $\checkmark$ & $\checkmark$ & $\checkmark$ & $\checkmark$ & $\checkmark$ & $\checkmark$ & $\checkmark$ & $\checkmark$ & $\checkmark$ & $\checkmark$ & $14 / 16$ \\
\hline $\begin{array}{l}\text { Nakagawa et } \\
\text { al., } 2008\end{array}$ & RCT-p & Level 2b & $\checkmark$ & $\checkmark$ & $\checkmark$ & $\checkmark$ & $\checkmark$ & $\checkmark$ & $\checkmark$ & $\checkmark$ & $\checkmark$ & $\checkmark$ & $\checkmark$ & $\checkmark$ & $\checkmark$ & $\checkmark$ & $\checkmark$ & $\checkmark$ & $15 / 16$ \\
\hline $\begin{array}{l}\text { Song et al., } \\
2009\end{array}$ & RCT & level 1b & $\checkmark$ & $\checkmark$ & $\checkmark$ & $\checkmark$ & $\checkmark$ & $\checkmark$ & $\checkmark$ & $\checkmark$ & $\checkmark$ & $\checkmark$ & $\checkmark$ & $\checkmark$ & $\checkmark$ & $\checkmark$ & $\checkmark$ & $\checkmark$ & $16 / 16$ \\
\hline $\begin{array}{l}\text { Tyler et al., } \\
2006\end{array}$ & $\mathrm{CS}$ & Level 2b & $\checkmark$ & $\checkmark$ & $\checkmark$ & $\checkmark$ & $\checkmark$ & $\checkmark$ & $\checkmark$ & $\checkmark$ & $\checkmark$ & $\mathrm{n} / \mathrm{a}$ & $\checkmark$ & $\checkmark$ & $\checkmark$ & $\checkmark$ & $x$ & $\checkmark$ & $14 / 16$ \\
\hline $\begin{array}{l}\text { Boling et al., } \\
2006\end{array}$ & CS & Level 2b & $\checkmark$ & $\checkmark$ & $\checkmark$ & $\checkmark$ & $x$ & $\checkmark$ & $\checkmark$ & $\checkmark$ & $\checkmark$ & $\mathrm{n} / \mathrm{a}$ & $\checkmark$ & $\checkmark$ & $\checkmark$ & $\checkmark$ & $\checkmark$ & $\checkmark$ & $14 / 15$ \\
\hline $\begin{array}{l}\text { Earl \& Hoch, } \\
2011 .\end{array}$ & $\mathrm{CSr}$ & Level 4 & $\checkmark$ & $\checkmark$ & $\checkmark$ & $\checkmark$ & $\checkmark$ & $\checkmark$ & $\checkmark$ & $\checkmark$ & $\checkmark$ & $\mathrm{n} / \mathrm{a}$ & $\checkmark$ & $\checkmark$ & $\checkmark$ & $\checkmark$ & $\checkmark$ & $\checkmark$ & $15 / 15$ \\
\hline \multirow[t]{2}{*}{$\begin{array}{l}\text { Ferber et al., } \\
2011\end{array}$} & CS & Level 4 & $\checkmark$ & $\checkmark$ & $\checkmark$ & $\checkmark$ & $\checkmark$ & $\checkmark$ & $x$ & $x$ & $\checkmark$ & $\checkmark$ & $\checkmark$ & $\checkmark$ & $\checkmark$ & $\checkmark$ & $x$ & $\checkmark$ & $13 / 16$ \\
\hline & & Total & 14 & 14 & 14 & 14 & 8 & 11 & 12 & 11 & 14 & 6 & 12 & 14 & 14 & 14 & 12 & 14 & \\
\hline
\end{tabular}

$\mathrm{RCT}=$ randomised controlled trial, $\mathrm{CCT}=$ comparative control trial $\mathrm{RCT}-\mathrm{p}=$ randomised controlled pilot study, $\mathrm{CS}=\mathrm{cohort}$ study, $\mathrm{CSr}=\mathrm{case}$ series:

\section{Key: ü= yes (criterion fulfilled), $x=$ No (criterion not fulfilled/not clear), n/a= Not applicable}

1. Is the study question and aims clear?; 2 . Is the background literature review adequate leading to the research questions and objectives?; 3 . Is the selected study design and study setting appropriate?; 4 . Is the study sample characteristic suitable?; 5 . Is the sample size adequate and justified?; 6. Is the study ethical?; 7. Is the reliability of outcome measures reported?; 8. Is the validity of outcome measures reported?; 9 . Is intervention descriptions clear and adequate?; 10. Was contamination of sample populations avoided?; 11. Is co-interventions are avoided?; 12 . Are results reported in terms of statistical significance?; 13. Were appropriate statistical analyses were performed?; 14 . Were clinical significance of the findings are reported?; 15. Were participants' drop-outs and withdrawals the reported?; 16. Are the author's conclusions appropriate?

Table 3: Participants allocation in intervention and non-intervention groups with the duration of intervention and frequency of therapy in weeks 


\begin{tabular}{|c|c|c|c|c|c|c|c|}
\hline Study & $\begin{array}{l}\text { Duration of } \\
\text { Intervention }\end{array}$ & $\begin{array}{l}\text { Frequency of } \\
\text { Therapy }\end{array}$ & $\operatorname{Hip}_{(N}$ & $\begin{array}{l}\text { Quad } \\
\text { (n) }\end{array}$ & $\begin{array}{l}\text { Hip-Quad } \\
\text { (n) }\end{array}$ & $\begin{array}{l}\text { No Exercise } \\
\text { (n) }\end{array}$ & $\begin{array}{l}\text { Total } \\
(\mathrm{N})\end{array}$ \\
\hline Dolak et al. 2011 & 4 Wks & 3 per Wk & 17 & 16 & & \multirow[t]{8}{*}{ - } & 33 \\
\hline Baldon et al.2014 & $8 \mathrm{Wks}$ & 3 per Wk & 15 & 16 & & & 31 \\
\hline $\begin{array}{l}\text { Khayambashi et al. } \\
2014\end{array}$ & $8 \mathrm{Wks}$ & 3 per Wk & 18 & 18 & & & 36 \\
\hline Nakagawa et al. 2008 & $6 \mathrm{Wks}$ & 4 per Wk & 7 & 7 & & & 14 \\
\hline Fukuda et al. 2010 & $4 \mathrm{Wks}$ & 3 per Wk & 20 & 21 & & & 41 \\
\hline Fukuda et al. 2012 & $4 \mathrm{Wks}$ & 3 per Wk & 24 & 25 & & & 49 \\
\hline Ismail et al. 2013 & $6 \mathrm{Wks}$ & 3 per Wk & 16 & 16 & & & 32 \\
\hline Avraham et al. 2007 & $3 \mathrm{Wks}$ & 2 per Wk & 10 & 10 & 10 & & 30 \\
\hline Song et al. 2009 & $8 \mathrm{Wks}$ & 3 per Wk & - & 30 & 29 & 30 & 89 \\
\hline $\begin{array}{l}\text { Khayambashi et al. } \\
2012\end{array}$ & 8 Wks & 3 per Wk & 14 & - & & 14 & 28 \\
\hline Total (N) & & & 74 & 157 & 108 & 44 & 383 \\
\hline
\end{tabular}

Table 4: Follow-up duration and interval post-intervention pain/functional outcome measures

\begin{tabular}{|llllll|}
\hline Authors & Immediately & 1-mo* & 3-mo & 6-mo & 12-mo \\
\hline Avraham et al., 2007 & $\checkmark$ & $\times$ & $\times$ & $\times$ & $\times$ \\
\hline Baldon et al., 2014 & $\checkmark$ & $\checkmark$ & $\times$ & $\times$ & $\times$ \\
\hline Dolak et al., 2011 & $\checkmark$ & $\times$ & $\times$ & $\times$ & $\times$ \\
\hline Fukuda et al., 2010 & $\checkmark$ & $\times$ & $\checkmark$ & $\checkmark$ & $\checkmark$ \\
\hline Fukuda et al., 2012 & $\checkmark$ & $\times$ & $\checkmark$ & $\checkmark$ & $\checkmark$ \\
\hline Ismail et al., 2013 & $\checkmark$ & $\times$ & $\times$ & $\times$ & $\times$ \\
\hline Khayambashi et al. 2014 & $\checkmark$ & $\times$ & $\times$ & $\checkmark$ & $\times$ \\
\hline Khayambashi et al. 2012 & $\checkmark$ & $\times$ & $\times$ & $\checkmark$ & $\times$ \\
\hline Nakagawa et al., 2008 & $\checkmark$ & $\times$ & $\times$ & $\times$ & $\times$ \\
\hline Song et al., 2009 & $\checkmark$ & $\times$ & $\times$ & $\times$ & $\times$ \\
\hline
\end{tabular}

${ }^{*}$,Month

Table 5: Evidence table for controlled clinical trials 


\begin{tabular}{|c|c|c|c|c|c|}
\hline $\begin{array}{l}\text { Authors } \\
\text { Study design }\end{array}$ & $\begin{array}{l}\text { Patient sample } \\
\text { size \& } \\
\text { characteristics }\end{array}$ & $\begin{array}{l}\text { Description of } \\
\text { interventions and setting }\end{array}$ & $\begin{array}{l}\text { Comparator exercise and } \\
\text { setting }\end{array}$ & $\begin{array}{l}\text { Follow-up } \\
\text { duration \& } \\
\text { outcome } \\
\text { measures }\end{array}$ & $\begin{array}{l}\text { Effect size \& summary } \\
\text { of key findings }\end{array}$ \\
\hline $\begin{array}{l}\text { Avraham et } \\
\text { al. (2007) } \\
\text { Single- } \\
\text { blinded } \\
\text { randomised } \\
\text { clinical trial } \\
\text { (A pilot trial) }\end{array}$ & $\begin{array}{l}\mathrm{N}=30 \text {; Patients } \\
\text { with a } \\
\text { confirmed } \\
\text { diagnosis of } \\
\text { PFP } \\
\\
\text { Ratio of male: } \\
\text { female not } \\
\text { indicated }\end{array}$ & $\begin{array}{l}\text { Hip group ( } \mathrm{N}=10 \text { ) } \\
\text { Participants underwent an } \\
\text { exercise program targeting } \\
\text { strengthening of hip } \\
\text { external rotators } \\
\text { 3-week exercise protocol } \\
\text { with supervision involved: } \\
90^{\circ} \text { knee flexion/extension } \\
\text { exercise, } \\
\text { hamstring/iliotibial band } \\
\text { stretches coupled with } \\
\text { electrotherapy } 2 \text { times per } \\
\text { week. } \\
\text { Hip/quadriceps group } \\
\text { (N=10) } \\
\text { Participants received } \\
\text { exercise targeting hip and } \\
\text { quadriceps musculature. } \\
\text { This was coupled with } \\
\text { electrotherapy } 2 \text { times per } \\
\text { week }\end{array}$ & $\begin{array}{l}\text { Quadriceps group ( } \mathbf{N}=10) \\
\text { Participants received } \\
\text { quadriceps strengthening } \\
\text { exercise involving: } \\
\text { straight leg raise (SLR), } \\
\text { single-leg squats coupled } \\
\text { with electrotherapy } 2 \\
\text { times per week }\end{array}$ & $\begin{array}{l}\text { Pain assessed } \\
\text { by numeric } \\
\text { visual analogue } \\
\text { scale (VAS) } \\
\text { Function } \\
\text { assessed by } \\
\text { Patello-Femoral } \\
\text { Joint Evaluation } \\
\text { Scale (PFJES) } \\
\text { Measured at } \\
\text { baseline and } 3 \\
\text { wks. post- } \\
\text { intervention }\end{array}$ & $\begin{array}{l}\text { All groups exhibited } \\
\text { significant improvements } \\
\text { in VAS and PFJES scores } \\
(p<0.0001) \text {. } \\
\text { Between-group } \\
\text { differences in pain and } \\
\text { function were not } \\
\text { statistically significant } \\
(p>0.05) \text {. }\end{array}$ \\
\hline & & $\begin{array}{l}\text { Setting: Rehabilitation } \\
\text { facility. }\end{array}$ & & & \\
\hline $\begin{array}{l}\text { Nakagawa et } \\
\text { al. (2008) } \\
\text { Prospective, } \\
\text { single-blinded } \\
\text { randomised } \\
\text { controlled } \\
\text { design }\end{array}$ & $\begin{array}{l}\text { Age range: } 17- \\
40 \text { yrs. [mean } \pm \\
\text { SD 23.6 } \pm 5.9 \\
\text { yrs.] } \\
\\
\text { Hip/quadriceps } \\
\text { group ( } n=7)- \\
\text { Group } \\
\text { characteristics } \\
\text { not defined } \\
\text { Quadriceps } \\
\text { group (n=7)- } \\
\text { Group } \\
\text { characteristics } \\
\text { not defined }\end{array}$ & $\begin{array}{l}\text { Hip/quadriceps group } \\
(\mathrm{N}=7) \\
\text { Hip/quadriceps protocol } \\
\text { involved strengthening of } \\
\text { hip abductors, lateral } \\
\text { rotators and transverse } \\
\text { abdominis coupled with } \\
\text { quadriceps protocol. }\end{array}$ & $\begin{array}{l}\text { Quadriceps group (N=7) } \\
\text { Quadriceps protocol } \\
\text { involved patellar } \\
\text { mobilization, stretching } \\
\text { of the quadriceps, } \\
\text { gastrocnemius, } \\
\text { hamstrings and iliotibial } \\
\text { band coupled with open } \\
\text { and closed kinetic chain } \\
\text { exercises for quadriceps } \\
\text { strengthening. }\end{array}$ & $\begin{array}{l}\text { Perceived pain } \\
\text { symptoms } \\
\text { during } \\
\text { functional } \\
\text { activities } \\
\text { assessed by } \\
\text { VAS } \\
\\
\text { Measured at } \\
\text { baseline and } 6 \\
\text { wks. post- } \\
\text { intervention }\end{array}$ & $\begin{array}{l}\text { The hip/quadriceps group } \\
\text { exhibited significant } \\
\text { improvement in pain } \\
\text { symptoms ( } p=0.02-0.04) \\
\text { except during prolonged } \\
\text { sitting: } \\
\text { Mean difference (at } 6 \\
\text { weeks-baseline) in usual } \\
\text { pain }-3.6 \pm 2.6\left(p=0.03^{*}\right) \text {, } \\
\text { worst pain }-2.6 \pm 2.5 \\
\left(p=0.03^{*}\right) \text {, } \\
\text { Stair climbing }-3.0 \pm 3.2 \\
\left.\text { ( } p=0.04^{*}\right) \text {, } \\
\text { Descending stair }- \\
4.1 \pm 2.9\left(p=0.03^{*}\right) \text {, and } \\
\text { Squatting }-5.4 \pm 3.0 \\
\left(p=0.02^{*}\right) \text { significant, but } \\
\text { not prolonged sitting }- \\
1.9 \pm 2.9(p=0.14) \text {. } \\
\\
\text { No significant pain } \\
\text { improvement in the } \\
\text { quadriceps group } \\
(P>0.05) \text {. }\end{array}$ \\
\hline $\begin{array}{l}\text { Randomised } \\
\text { controlled } \\
\text { trial }\end{array}$ & $\begin{array}{l}\mathrm{N}=89 ;(69 \\
\text { females and } \\
20 \text { males) } \\
\text { with a } \\
\text { confirmed } \\
\text { diagnosis of } \\
\text { PFP }\end{array}$ & $\begin{array}{l}\text { LPHA group ( } \mathbf{N}=29) \\
\text { 50-N isometric hip } \\
\text { adduction/abduction for } \\
\text { strengthening hip } \\
\text { abductors coupled with } \\
\text { leg-press exercise for } \\
\text { quadriceps strengthening. }\end{array}$ & $\begin{array}{l}\text { LP group }(\mathrm{N}=30) \\
\text { Leg-press exercise } \\
\text { performed unilaterally } \\
\text { from } 45^{\circ} \text { of knee flexion } \\
\text { to full extension assisted } \\
\text { by an EN-Dynamic Track } \\
\text { machine. }\end{array}$ & $\begin{array}{l}\text { Worst pain in } \\
\text { the previous } \\
\text { week rated on a } \\
10-c m \text { visual } \\
\text { analogue scale } \\
\text { (VAS-W). Knee } \\
\text { function } \\
\text { evaluated by } \\
\text { Tegner Lysholm } \\
\text { Knee Scoring } \\
\text { Scale }\end{array}$ & $\begin{array}{l}\text { The LPHA group: } \\
\text { Exhibited significant } \\
\text { improvements in VAS-W } \\
\text { ratings }(p<0.005) \text { with } \\
\text { mean difference of } 2.18 \\
\text { (3.17-1.19; } 95 \% \mathrm{CI}) \text { and } \\
\text { Tegner Lysholm } \\
\text { (p<0.005) with a mean } \\
\text { score difference of } 10.93 \\
\text { (7.27 to } 14.59 ; 95 \% \mathrm{Cl})\end{array}$ \\
\hline
\end{tabular}


Mean age: 41

yrs.

Hip

adduction/leg-

press Exercise

(LPHA) group:

$(\mathrm{N}=29)-(8$

men; 21

women); Mean

\pm SD age: 38.6

\pm 10.8 yrs.

Mean \pm SD

duration of

symptoms:

$41.8 \pm 36.1$

months

Leg-press

Exercise only

(LP) group

$(\mathrm{N}=30)$ - (8

men; 22

women); Mean

\pm SD age: 40.2

\pm 9.9 yrs.

Mean \pm SD

duration of

symptoms:

$38.3 \pm 34.2$

months

\section{No Exercise}

group $(\mathrm{N}=30)$

-(4 men; 26

women); Mean

\pm SD age: 43.9

\pm 9.8 yrs.

Mean \pm SD

duration of

symptoms:

$27.7 \pm 41.0$

months

\section{Fukuda et al. $\quad \mathrm{N}=54$ \\ (2010) \\ (females) \\ Sedentary}

women

Randomised with a

controlled

confirmed

diagnosis of

PFP

Age range:

20-40 yrs.

Knee and hip

Exercise (KHE)

group $(\mathrm{N}=25)$;

Mean \pm SD age: $22 \pm 3$ yrs

Mean \pm SD

duration of

symptoms:

$23.2 \pm 19.0$

months
3 weekly sessions for 8

wks. with full supervision

Setting: Clinical

(kinesiology laboratory)

Setting: Clinica

(kinesiology laboratory)

\section{No exercise group: $(\mathrm{N}=30)$}

Given health educational materials on PFP selfefficacy

Advised not to enrol in any exercise program during the study period
Follow-up: Immediately and at 8 wks. postintervention
LP group:

Significant improvements in VAS-W ratings $(\mathrm{p}<0.005)$ with mean difference of 2.58 (3.561.61) and Tegner Lysholm scale $(p<0.005)$ with a mean score difference of 10.93 (7.27$14.59 ; 95 \% \mathrm{Cl}$ ).

Non-exercise group had no significant pain improvements $(\mathrm{p}=0.714$ 0.715)

Effect difference between LPHA and LP was not significant in VAS-W ratings $(p=0.577)$ and TLKSS $(p=0.776)$, respectively

\section{KHE group ( $\mathrm{N}=25)$ \\ Knee exercise coupled with hip abductor and lateral rotator strengthening}

Exercise protocol included hip abduction against elastic band while standing or with weights in the side-lying position.

Hip lateral rotation against elastic band while seated and hip extension.

It was coupled with knee exercise for the KE group.

3 sessions per week for 4 weeks

Setting: Rehabilitation facility.

\section{KE group ( $\mathrm{N}=24)$}

Hamstrings/plantar flexors/quadriceps/ iliotibial band stretches.

Knee extension at an angle of $90^{\circ}$ to $45^{\circ}$,

Leg presses and squats at an angle of $0^{\circ}$ to $45^{\circ}$, single-leg calf raises, and prone knee flexion

3 sessions per week for 4 weeks

Setting: Rehabilitation facility.
Pain assessed by 11-point NPRS during ascending and descending stairs

Knee function assessed by LEFS and AKPS

Follow-up:

at 3,6 , and 12

months postintervention
Within KHE group change in mean NPRS scores:

For ascending stairs at 3 , 6 and 12 months posttreatment were $-5.0 \pm 1.5$ $(95 \%$ Cl: $-5.6,-4.4),-4.5$ \pm 1.4 (95\% Cl: -5.0 , $4.0)$ and $-3.3 \pm 1.1$ (95\% Cl: $-3.7,-2.9)$, respectively; $(p<.05)$.

For descending stairs at 3,6 and 12 months posttreatment were $-4.2 \pm 1.7$ (95\% Cl: $-4.9,-3.5),-3.8$ \pm 1.4 (95\% Cl: $-4.4-32$ ) and $-3.3 \pm 1.1(95 \% \mathrm{Cl}:-$ $3.7,-29)$, respectively: $(\mathrm{p}<.05)$.

\section{Within KE group change} in mean NPRS scores:

For ascending stairs at 3 , 6 and 12 months post treatment were $-1.3 \pm 1.2$ $(95 \%$ Cl: $-2.9,0.3),-1.1$ \pm 1.1 (95\% Cl: $-1.6,-0.6)$ and $-0.1 \pm 1.0(95 \% \mathrm{Cl}$ : - 
Knee

Exercise (KE)

group $(\mathrm{N}=24)$;

Mean $\pm S D$ age:

$23 \pm 3$ yrs.

Mean \pm SD

duration of

symptoms:

$21.0 \pm 17.7$

months

$0.7,0.5)$, respectively: $(p<.05)$

For descending stairs at 3,6 and 12 months posttreatment were $-1.4 \pm 0.9$

(95\% Cl: $-1.7,-1.1),-0.8$ \pm 0.9 (95\% Cl: $-1.2,-0.4$ ), and $0.0 \pm 0.9(95 \% \mathrm{Cl}:-$ $0.3,0.3)$, respectively.

Within KHE group change in mean LEFS scores: at 3,6 and 12 months posttreatment were 22.4 \pm 10.5 (95\% Cl: $18.4,26.4$ ), $20.7 \pm 11.0$ (95\% Cl: 16.5 , $24.9)$, and $17.9 \pm 9.7(95 \%$ Cl: 14.2, 21.6)

respectively: $(p<.05)$.

Within KE group change in mean LEFS scores: at 3,6 and 12 months posttreatment were $0.4 \pm 5.2$

$(-1.7,2.5)-1.3 \pm 5.3(-$ $3.4,2.1)-2.9 \pm 4.9(-4.9$ $-0.9)$, respectively.

For descending stairs at 3,6 and 12 months posttreatment were $-1.4 \pm 0.9$ (95\% Cl: $-1.7,-1.1),-0.8$ \pm 0.9 (95\% Cl: $-1.2,-0.4)$, and $0.0 \pm 0.9(95 \% \mathrm{Cl}:-$ $0.3,0.3)$, respectively: $(\mathrm{p}<.05)$.

Within KHE group change in mean AKPS scores: at 3,6 and 12 months posttreatment were $19.8 \pm 9.1$ (95\% Cl: 16.2, 23.4), 15.8 \pm 8.1 (95\% Cl: $12.6,19.0)$ and $13.1 \pm 8.3$ (95\% Cl: 9.8, 16.4), respectively: $(p<.05)$.

Within KE group change in mean AKPS scores: at 3,6 and 12 months posttreatment were $2.8 \pm 8.9$ (95\% Cl: $-0.7,6.3) 0.2$ \pm 8.4 (95\% Cl: $-3.2,3.6)$, and $-1.8 \pm 8.4(95 \% \mathrm{Cl}:-$ $5.1,1.5)$, respectively: $(p<.05)$.

*Overall KHE outcomes were superior over those of the KE group $(p<.05)$.

\section{Dolak et al.} (2011)

Randomised Clinical Trial
$\mathrm{N}=33$; Females

with a

confirmed

diagnosis of

PFP.

Age range: 16$35 \mathrm{yrs}$.

Hip group

$(\mathrm{N}=17)$ Mean age: $25 \pm 5$ yrs.

Mean $\pm S D$ duration of

\section{Hip group ( $\mathrm{n=17})$}

Hip protocol involved combined hip abduction and external rotation in side-lying and standing positions coupled with seated hip external rotation.

Participants supervised during 1 session and unsupervised during 2 weekly home-based sessions for 4 weeks.

\section{Quadriceps group $(n=16) \quad$ Pain: VAS-W}

Quadriceps protocol involved quad sets, short-arc quads, straight leg raises and terminal knee extensions

This protocol performed for 4 consecutive weeks with full supervision

Setting: Rehabilitation facility and home. AKPS

Follow-up: Immediately

Outcome measured at
Hip group exhibited significant improvements in pain: $47.9 \%(\mathrm{p}<0.001)$ and knee function:

Function: LEFS, baseline and 4 $18.7 \%(p<0.001)$.

\section{Quadriceps} group exhibited significant improvements in knee function (9.3\%; $\mathrm{p}<0.001$ ) but not pain $(p=0.88)$

Pain significantly reduced in the hip group 
symptoms: 36 \pm 34 months

Setting: Rehabilitation facility and home weeks postintervention

compared to the quadriceps group with a mean difference of 1.7 $(p=0.035)$

No significant difference in knee function $(p>0.05)$ between the two groups at the end of the study.

Pain: 11-point NPRS during $(\mathrm{N}=25)$

\section{Quadriceps group $(\mathrm{N}=24)$}

Hip abductor and external rotators coupled with quadriceps strengthening/ stretching knee exercise: seated knee extension, leg press, squatting, stretching of hamstrings, quadriceps, ankle plantar flexors and iliotibial band

20-40 yrs.

Hip/quadriceps group $(n=25)$

Mean $\pm S D$ age: $22.0 \pm 3.0$ yrs

Mean $\pm S D$ duration of symptoms:

$23.2 \pm 19.0$

months

Quadriceps

group

$(\mathrm{n}=24)$ Mean

\pm SD age: 23.0

\pm 3.0 yrs.

Mean \pm SD

duration of

symptoms:

$21.0 \pm 17.7$

months

3 sessions per week for 4 weeks

Setting: Rehabilitation facility.
Quadriceps

strengthening/stretching

knee exercise; seated

knee extension, leg press, squatting, stretching of

hamstrings, quadriceps, ankle, plantar flexors and iliotibial band

Setting: Rehabilitation
acility.

ascending and descending

stairs

Function: LEFS, AKPS

At baseline

Follow-up: immediately and post-intervention at 3,6 , and 12 months.

\section{For interventional group:}

Pain during upstairs gait reduced to $80.7 \%$ (p $<0.05$ ) at 3 months, $73.2 \%(\mathrm{p}<0.05)$ at 6 months and $53.2 \%$ (p $<0.05$ ) at 12 months

Pain during downstairs gait reduced to $72.4 \%$ (p $<0.05$ ) at 3 months, 65.5 $\%(p<0.05)$ at 6 months and $56.9 \%(p<0.05)$ at 12 months

Knee function score on AKPS improved to $30.1 \%$ ( $p<0.05$ ) at 3 months, $20.4 \%(p<0.05)$ at 6 months and $19.9 \%$ (p $<0.05)$ at 12 months

\section{For comparator group:}

Pain during downstairs gait reduced to $21.9 \%$ ( $p$ $<0.05)$ at 3 months, $12.5 \%(p<0.05)$ at 6 months.

At 6 months pain during upstairs gait reduced to $16.7 \%(p<0.05)$

No significant change in both AKPS and LEFS scores at 3,6 and 12 months.

\section{For hip exercise group:}

Participants also prescribed $1000 \mathrm{mg}$ of Omega-3 and $400 \mathrm{mg}$ of calcium daily for 8 weeks.

Supervised isolated hip external rotator

strengthening to $30^{\circ}$ in the seated position.

+SD age:

$28.9 \pm 5.8 \mathrm{yrs}$.

Duration of symptoms: not indicated

Exercise protocol performed 3 times per week for 8 weeks.

\section{Non-exercise}

group

$(\mathrm{N}=14) ;$ Mean

\pm SD age: 30.5

$4.8 \pm 3.2 \mathrm{yrs}$.

Duration of symptoms: not indicated
Setting: Rehabilitation facility.
Worst pain in the previous week assessed by VAS

Self-reported health status assessed by the Western Ontario and McMaster Universities (WOMAC) questionnaire.

VAS and WOMAC scores recorded at baseline (preintervention) week 8 (postintervention), and 6 months postintervention.
Exhibited significant improvements in VAS score $(p<0.001)$ :

Mean VAS score difference from baseline $(7.9 \pm 1.7)$ to 8 wk. postintervention (1.4 \pm 1.9$)$ was $-6.4 \pm 2.7 ; 95 \% \mathrm{Cl}$ : $7.9,-4.9(p<0.001)$.

Mean VAS score difference from baseline $(7.9 \pm 1.7)$ to 6 months post-intervention

$(1.7 \pm 2.7)$ was $-6.2 \pm 1.4$; 95\% Cl: $-7.9,-4.3$ ( $<0.001)$.

Significant improvements were seen in WOMAC score $(p<0.001)$ : 
Mean WOMAC score difference from baseline $(54.0 \pm 18.1)$ to $8 \mathrm{wk}$. post intervention $(10.7 \pm 16.1)$

was $-43.3 \pm 20.1 ; 95 \%$ Cl: $-54.9,-31.7$

$(p<0.001)$.

Mean WOMAC score difference from baseline $(54.0 \pm 18.1)$ to 6 months post-intervention (10.8 $\pm 17.7)$ was $-43.2 \pm 7.7$; 95\% Cl: $-55.9,-30.0$ (p $<0.001$ ).

Non-exercise group:

No noticeable improvements in VAS and WOMAC scores $(p>0.05)$.

\begin{tabular}{|c|c|}
\hline $\begin{array}{l}\text { Prospective } \\
\text { randomised } \\
\text { controlled } \\
\text { trial }\end{array}$ & $\begin{array}{l}\mathrm{N}=32 ;(23 \\
\text { females } 9 \\
\text { males); with a } \\
\text { confirmed } \\
\text { diagnosis of } \\
\text { PFP }\end{array}$ \\
\hline \multirow{7}{*}{$\begin{array}{l}\text { Prospective } \\
\text { randomised } \\
\text { controlled } \\
\text { trial }\end{array}$} & $\begin{array}{l}\text { Age range 18- } \\
30 \text { yrs. }\end{array}$ \\
\hline & $\begin{array}{l}\text { Closed kinetic } \\
\text { chain (CKC) + } \\
\text { hip exercise } \\
\text { (CKCH) group } \\
(\mathrm{n}=16) ;(11 \\
\text { women, } 5 \text { men) }\end{array}$ \\
\hline & $\begin{array}{l}\text { Mean } \pm \text { SD age: } \\
20.8 \pm 2.7 \text { yrs. }\end{array}$ \\
\hline & $\begin{array}{l}\text { Mean } \pm S D \\
\text { duration of } \\
\text { symptoms: not } \\
\text { indicated }\end{array}$ \\
\hline & $\begin{array}{l}\text { CKC group } \\
(n=16) ;(12 \\
\text { women, } 4 \text { men })\end{array}$ \\
\hline & $\begin{array}{l}\text { Mean } \pm \text { SD age: } \\
21.2 \pm 3.2 \text { yrs. }\end{array}$ \\
\hline & $\begin{array}{l}\text { Mean } \pm S D \\
\text { duration of } \\
\text { symptoms: not } \\
\text { indicated }\end{array}$ \\
\hline
\end{tabular}

Hip abductors and lateral rotators strengthening exercise coupled with CKC exercises for hip/quadriceps strengthening

Hip abductor strengthening performed in a side-lying position on the nonaffected side.

Lateral rotators strengthening performed while seated and hip flexed to $90^{\circ}$

Training sessions: 3 times per week for 6 weeks

Setting: Rehabilitation facility.

\section{CKCH group $(n=16)$}

\section{CKC group $(n=16)$}

Closed kinetic chain exercises for quadriceps strengthening

Protocol involved stretching of hamstrings, Knee function iliotibial band and gastrocnemius.

Also involved mini wall squats, forward/lateral step-ups and terminal knee extensions.

Training sessions: 3 times per week for 6 weeks

Setting: Rehabilitation facility.
Worst pain in the previous week assessed by VAS assessed by AKPS

Follow-up: Immediately

Outcome baseline and 6 weeks postintervention measured at

\section{For CKCH group:}

Significant improvements in VAS and Kujala scores $(p<0.05)$.

Mean VAS score difference from baseline $(5.3 \pm 1.6)$ to 6 wk. $(2.0$ $\pm 1.1)$ post-intervention $3.2 \pm 0.9$.

Mean Kujala score difference from baseline $(71.5 \pm 7.8)$ to 6 wk. (85.1 \pm 6.2 ) post-intervention

\section{$13.7 \pm 5.5$}

\section{For CKC group:}

Significant improvements in VAS and Kujala scores $p<0.05$ )

Mean VAS score difference from baseline $(4.5 \pm 1.8)$ to 6 wk. $(2.3$ $\pm 1.1)$ post-intervention $2.26 \pm 1.3$.

Mean Kujala score difference from baseline $(76.4 \pm 10.4)$ to $6 \mathrm{wk}$. $(85.0 \pm 6.7)$ postintervention $8.6 \pm 7.3$

*Overall pain and function outcome in the $\mathrm{CKCH}$ group was superior to the CKC group ( $\mathrm{p}$ $<0.05$ )

For Hip exercise group:

Hip extension/lateral

Randomised, comparativecontrolled single-blinded study rotation in prone, sidelying, standing

$\mathrm{N}=31$

(Females); with a confirmed PFP

Age range: 1830 yrs.

Hip exercise group (n=15); Mean \pm SD

age:27.7 $\pm 3.2 \quad$ Pelvic drop in standing yrs.:

Mean duration of symptoms:
Isometric hip abduction/ lateral rotation in standing knee and hip flexion in side-lying 75 to 90 minutes with

Hamstrings, soleus, gastrocnemius, and

Sessions performed 3
Worst-pain in the previous week rated on $10 \mathrm{~cm}$ - VAS and lateral retinaculum stretches iliotibial band stretches times a week for 8 wks.)

Knee function: LEFS

Baseline, immediately and 3-month postintervention
Mean differences in VAS score at end of intervention $(-5.2 \pm 1.6)$ and 3-months postintervention $(-5.7 \pm 2.3)$ were significant $\left(p<0.05^{\star}\right)$. Pain reduced.

Mean difference in LEFS at end of intervention ($18.9 \pm 12.5$ ) and 3-months post-intervention -19.5 \pm 11.9 ) were significant ( $p$ 
not indicated

Quadriceps

group

(n=16); Mean

$\pm \mathrm{SD}$

age:21.3 \pm 2.6

yrs.:

Mean duration of symptoms:

not indicated
Hip lateral rotation in closed kinetic chain

Plus the standard knee exercise

Sessions performed 3 times a week for 8 wks.)

Sessions lasted between 90 to 120 minutes with supervision by a physical therapist

Setting: Laboratory of Intervention and Orthopaedics and Traumatology laboratory supervision by a physical therapist

$\left.<0.05^{\star}\right)$. Knee function improved

Setting: Laboratory of Intervention and Orthopaedics and Traumatology laboratory

\section{For quadriceps group:}

Pain improved significantly ( $p<0.05)$, but not knee function ( $p$ $>0.05$ )

Mean difference in VAS at the end of intervention ($3.0 \pm 2.4)$ and 3-months post-intervention $(-3.6$ \pm 3 .3) were significant ( $p$ $<0.05)$.

Mean difference in LEFS score at the end of intervention $(-12.9 \pm 7.5)$ and 3-months postintervention $(-12.7 \pm 6.2)$ was not significant ( $p$ $>0.05$ ).

Between-group difference in VAS scores only significant at 3-months post-intervention ( $p$ $<0.05$ ).

Between-group differences not significant in VAS at any time-point

$\begin{array}{ll}\text { Khayambashi } & \mathrm{N}=36(18 \text { men, } \\ \text { et al. (2014) } & \begin{array}{l}18 \text { women); } \\ \text { with clinical } \\ \text { diagnosis of }\end{array} \\ & \text { PFP }\end{array}$

Comparative control trial

Hip exercise group $(n=18) ;(9$ men and 9 women) Mean \pm SD age: $28.2 \pm 7.9$ yrs.

Mean duration of symptoms: not indicated

Quadriceps group

(n=18); (9 men and 9 women) Mean \pm SD age: $27.3 \pm 6.7 y$ rs

Mean duration of symptoms: not indicated

\section{Hip exercise group $(n=18)$}

Underwent supervised exercise programs targeting hip muscles strengthening.

Hip exercise protocol included hip abductor and external rotator strengthening exercises in side-lying and knee flexed to $90^{\circ}$ while seated, respectively.

Quadriceps protocols include knee flexion to $30^{\circ}$ coupled with partial squats.

3 times a week for 8 wks.

Setting: Rehabilitation facility

\section{Quadriceps group ( $n=18)$}

Received supervised quadriceps strengthening exercises ( 3 times a week for $8 w k s)$.

Quadriceps protocols included knee flexion to $30^{\circ}$ coupled with partial squats.

Setting: Rehabilitation facility
Worst pain in

the previous week assessed by VAS

Self-reported health status assessed using the WOMAC questionnaire.

VAS and WOMAC scores recorded at baseline (preintervention), week 8 (postintervention) and 6 months postintervention difference from baseline

\section{For Hip exercise group:}

Significant improvements in VAS and WOMAC scores $(p<0.001)$ :

Mean VAS score difference from baseline $(7.63 \pm 1.79)$ to $8 w k$. $(2.11 \pm 1.6)$ and 6 months $(2.00 \pm 1.97)$ postintervention was -5.53 $\pm 1.60 ; 95 \% \mathrm{Cl}$ and -5.64 $\pm 1.99 ; 95 \% \mathrm{Cl}$ respectively $(p<0.001)$.

Mean WOMAC score $(46.83 \pm 21.86)$ to $8 \mathrm{wk}$.

$(6.22 \pm 3.87)$ and 6 months (6.94 \pm 5.70$)$ postintervention was -40.61 $\pm 20.68 ; 95 \% \mathrm{Cl}$ and $39.89 \pm 21.35$; $95 \% \mathrm{Cl}$, respectively $(p<0.001)$.

\section{For Quadriceps group:}

Significant improvements in VAS and WOMAC scores $(p<0.001)$ :

Mean VAS score difference from baseline $(6.91 \pm 1.94)$ to $8 w k$ $(3.27 \pm 2.19)$ and 6 months (4.00 \pm 2.44$)$ postintervention was -3.64 $\pm 1.39 ; 95 \% \mathrm{Cl}$ and -2.92 $\pm 1.72 ; 95 \% \mathrm{Cl}$ respectively $(p<0.001)$.

Mean WOMAC score difference from baseline $(44.11 \pm 22.05)$ to $8 w k$. 
$(21.89 \pm 16.55)$ and 6

months $(23.16 \pm 14.15)$

post-intervention was -

$22.22 \pm 10.59 ; 95 \% \mathrm{Cl}$ and $-20.94 \pm 14.30 ; 95 \% \mathrm{Cl}$, respectively $(p<0.001)$.

*Between-group difference was

statistically significant $p$ $\leq 0.05$, where outcomes

in the hip group were

superior over the

quadriceps group.

Table 6: Descriptions and critique of the reviewed 10 controlled clinical trials (CCTs) 


\begin{tabular}{|c|c|c|c|}
\hline Authors & $\begin{array}{l}\text { Study } \\
\text { design }\end{array}$ & $\begin{array}{l}\text { level of } \\
\text { evidence }\end{array}$ & critique \\
\hline $\begin{array}{l}\text { Avraham et al., } \\
2007\end{array}$ & RCT & Level 2b & $\begin{array}{l}\checkmark \text { Inadequate sample size (pilot study) } \\
\checkmark \text { Participants were not truly randomized to the three intervention groups } \\
\checkmark \text { Allocation concealment probably not done } \\
\checkmark \text { The physiotherapist who assessed the patients was blinded to the study } \\
\checkmark \text { Blinding of outcome assessment achieved by using patient-reported outcomes on VAS for } \\
\text { patellofemoral pain } \\
\checkmark \text { Evaluation scale PES }\end{array}$ \\
\hline Baldon et al., 2014 & RCT & level 1b & $\begin{array}{l}\checkmark \text { Participants recruited a/c to sample power estimation } \\
\checkmark \text { Participants were truly randomized by random sequences in a block randomization } \\
\text { manner } \\
\checkmark \text { Allocation concealment evident } \\
\checkmark \text { Double blinding evident (participants and therapists) } \\
\checkmark \text { Blinding of outcome assessment evident because the only patient-reported pain and } \\
\text { function outcomes collected. }\end{array}$ \\
\hline Dolak et al., 2011 & RCT & level 2b & $\begin{array}{l}\checkmark \text { Inadequate sample power } \\
\checkmark \text { Participants truly randomized by random sequence or block randomization } \\
\checkmark \text { Allocation concealment evident with a random number } \\
\checkmark \text { Outcome assessors partially blinded to participants (probable detection bias) } \\
\checkmark \text { Outcome assessment blinded (the only patient-reported pain and function outcomes } \\
\text { recorded). }\end{array}$ \\
\hline Fukuda et al., 2010 & RCT & level $1 \mathrm{~b}$ & $\begin{array}{l}\checkmark \text { Participants recruited a/c to sample power calculation } \\
\checkmark \text { Participants truly randomized } \\
\checkmark \text { Allocation concealment not evident } \\
\checkmark \text { Therapists not blinded } \\
\checkmark \text { Incomplete outcome data managed by intention-to-treat analysis } \\
\checkmark \text { Outcome assessment blinded (the only patient-reported pain and function outcomes } \\
\text { recorded). }\end{array}$ \\
\hline Fukuda et al., 2012 & RCT & level $1 \mathrm{~b}$ & $\begin{array}{l}\checkmark \text { Participants recruited based on the calculated sample power } \\
\checkmark \text { Participants were truly randomized } \\
\checkmark \text { Allocation concealment not evident } \\
\checkmark \text { Therapists not blinded } \\
\checkmark \text { Incomplete outcome data managed by intention-to-treat analysis } \\
\checkmark \text { Outcome assessment blinded (the only patient-reported pain and function outcomes } \\
\text { recorded). }\end{array}$ \\
\hline Ismail et al., 2013 & RCT & Level 2b & $\begin{array}{l}\checkmark \text { Inadequate sample power (Estimated sample power size not followed) } \\
\checkmark \text { Random allocation of participants concealed } \\
\checkmark \text { Therapists and assessors blinded to group allocation details } \\
\checkmark \text { Outcome assessment blinded (the only patient-reported pain and functional outcomes) }\end{array}$ \\
\hline $\begin{array}{l}\text { Khayambashi et al. } \\
2014\end{array}$ & CCT & Level 2b & $\begin{array}{l}\checkmark \text { Inadequate sample power } \\
\checkmark \text { Participants not allocated to restive groups by random allocation } \\
\checkmark \text { Participants and therapists not blinded } \\
\checkmark \text { Outcome assessment blinded (the only patient-reported pain and functional outcomes) }\end{array}$ \\
\hline
\end{tabular}

Page 22/30 


\begin{tabular}{|c|c|c|c|}
\hline $\begin{array}{l}\text { Khayambashi et al. } \\
2012\end{array}$ & RCT & Level 2b & $\begin{array}{l}\checkmark \text { Inadequate sample power } \\
\checkmark \text { Participants random allocation not followed } \\
\checkmark \text { Participants and therapists not blinded } \\
\checkmark \text { Outcome assessment blinded (the only patient-reported pain and functional outcomes) }\end{array}$ \\
\hline $\begin{array}{l}\text { Nakagawa et al., } \\
2008\end{array}$ & RCT-p & Level 2b & $\begin{array}{l}\checkmark \text { Inadequate sample size (pilot study) } \\
\checkmark \text { Group allocation concealed using sealed envelopes } \\
\checkmark \text { Therapist not blinded } \\
\checkmark \text { Principle investigator partially blinded (only at baseline phase) } \\
\checkmark \text { Blinded assessors employed }\end{array}$ \\
\hline Song et al., 2009 & RCT & level 1b & $\begin{array}{l}\checkmark \text { Participants randomized to group } \\
\checkmark \text { Participants and therapists blinded }\end{array}$ \\
\hline
\end{tabular}

$R C T$, randomised controlled trial; CCT, comparative control trial; RCT-p, randomised controlled pilot study; CS, cohort study; CSr, case series

Table 7: Evidence table for follow-up studies (cohort, case-control, case series and case reports) 


\begin{tabular}{|c|c|c|c|c|c|}
\hline $\begin{array}{l}\text { Authors } \\
\text { Study } \\
\text { design }\end{array}$ & $\begin{array}{l}\text { Patient sample } \\
\text { size \& } \\
\text { characteristics }\end{array}$ & $\begin{array}{l}\text { Description of interventions } \\
\text { and setting }\end{array}$ & $\begin{array}{l}\text { Comparator } \\
\text { exercise and } \\
\text { setting }\end{array}$ & $\begin{array}{l}\text { Follow-up duration } \\
\& \text { outcome } \\
\text { measures }\end{array}$ & $\begin{array}{l}\text { Effect size \& summary } \\
\text { of key findings }\end{array}$ \\
\hline $\begin{array}{l}\text { Boling et al. } \\
(2006)\end{array}$ & $\begin{array}{l}\mathrm{N}=28 \text {; } \\
\text { Participants } \\
\text { with and } \\
\text { without PFP. } \\
\text { Age range: 18- } \\
42 \text { yrs. } \\
\text { Experimental } \\
\text { group ( } \mathrm{n}=14) \\
\text { participants } \\
\text { with a } \\
\text { confirmed } \\
\text { diagnosis of } \\
\text { PFP (5 men, } 9 \\
\text { women) } \\
\text { Mean } \pm S D \text { age: } \\
24 \pm 6 \text { yrs. } \\
\text { Mean } \pm S D \\
\text { duration of } \\
\text { symptoms: } 22 \\
\pm 25 \text { months } \\
\text { Control group } \\
\text { (n=14) healthy } \\
\text { participants }(5 \\
\text { men and } 9 \\
\text { women) } \\
\text { Mean } \pm S D \text { age: } \\
23 \pm 2 \text { yrs. }\end{array}$ & $\begin{array}{l}\text { All participants received weight- } \\
\text { bearing exercises focusing on } \\
\text { strengthening of hip abductors, } \\
\text { gluteus medius, and quadriceps } \\
\text { strengthening coupled with lower- } \\
\text { extremity neuromuscular control for } 6 \\
\text { weeks. } \\
\text { Setting: Musculoskeletal research } \\
\text { laboratory }\end{array}$ & $\mathrm{N} / \mathrm{A}$ & $\begin{array}{l}\text { VAS and } \\
\text { Functional Index } \\
\text { Questionnaire } \\
\text { (FIQ) administered } \\
\text { at pre-test and } \\
\text { post-test and the } \\
\text { end of every week } \\
\text { of the 6-wk } \\
\text { intervention. }\end{array}$ & $\begin{array}{l}\text { At the end of the } \\
\text { intervention, the PFP } \\
\text { participants exhibited } \\
\text { significant improvements in } \\
\text { both VAS ( } p=0.001) \text { and FIQ } \\
(p=0.001) \text { scores from the } \\
\text { baseline. } \\
\text { Based on Post hoc analyses, } \\
\text { no significant changes in } \\
\text { both VAS and FIQ scores } \\
\text { were observed in the control } \\
\text { group. }\end{array}$ \\
\hline $\begin{array}{l}\text { Ferber et al. } \\
\text { (2011) } \\
\text { Cohort } \\
\text { study (Pre- } \\
\text { test and } \\
\text { post-test) }\end{array}$ & $\begin{array}{l}\mathrm{N}=25 ; \\
\text { Participants } \\
\text { with and } \\
\text { without PFP. } \\
\text { Experimental } \\
\text { group ( } n=15) \\
\text { participants } \\
\text { with a } \\
\text { confirmed } \\
\text { diagnosis of } \\
\text { PFP (5 men, } \\
10 \text { women) } \\
\text { Mean } \pm \text { SD age: } \\
35.2 \pm 12.2 \text { yrs } \\
\text { Mean duration } \\
\text { of symptoms } \\
\text { not indicated. } \\
\text { Control group } \\
\text { (n=10) Healthy } \\
\text { participants (4 } \\
\text { men and } 6 \\
\text { women) } \\
\text { Mean } \pm S D \text { age: } \\
29.9 \pm 8.3 \text { yrs } \\
\text { Mean duration } \\
\text { of symptoms } \\
\text { not indicated. }\end{array}$ & $\begin{array}{l}\text { Experimental group completed a 3- } \\
\text { week exercise training targeting the } \\
\text { strengthening of hip-abductor } \\
\text { muscles. } \\
\text { Setting: University-based clinical } \\
\text { research laboratory }\end{array}$ & $\begin{array}{l}\text { No } \\
\text { exercises }\end{array}$ & $\begin{array}{l}\text { Hip abductor } \\
\text { muscle strength } \\
\text { and pain (VAS) } \\
\text { measured at } \\
\text { baseline and after } \\
\text { 3-week training. }\end{array}$ & $\begin{array}{l}\text { 3-week hip-abductor muscle- } \\
\text { strengthening protocol } \\
\text { administered to participants } \\
\text { with PFP was effective in } \\
\text { increasing isometric muscle } \\
\text { strength, which improved by } \\
32.69 \% \text { from baseline ( } \mathrm{p}= \\
0.04) \text {. } \\
\\
\text { Mean difference between } \\
\text { pre-training and post- } \\
\text { training VAS scores was } \\
3.30 \pm 1.90,(\mathrm{p}=0.01) \text { which } \\
\text { translated into } 43.10 \% \\
\text { reduction in VAS score. }\end{array}$ \\
\hline $\begin{array}{l}\text { Case series; } \\
\text { Level of } \\
\text { evidence, } 4\end{array}$ & $\begin{array}{l}\mathrm{N}=19 \text {; Women } \\
\text { with a } \\
\text { confirmed } \\
\text { diagnosis of } \\
\text { PFP } \\
\text { Age range 16- } \\
40 \text { yrs. }\end{array}$ & $\begin{array}{l}\text { Completed 8-weeks exercise program } \\
\text { targeting hip and core muscles } \\
\text { strengthening and improving } \\
\text { dynamic malalignment. } \\
\text { Exercises were administered in } 3 \\
\text { phases: } \\
\text { Phase I: Abdominal draw-in exercises, } \\
\text { side-lying clamshells /straight-leg }\end{array}$ & $\mathrm{N} / \mathrm{A}$ & $\begin{array}{l}\text { Pain and function } \\
\text { assessed at } \\
\text { baseline, } 8 \text { weeks } \\
\text { and } 6 \text { months } \\
\text { post-training } \\
\text { Pain assessed by } \\
\text { VAS }\end{array}$ & $\begin{array}{l}\text { Significant improvements in } \\
\text { pain and functional ability } \\
(p<0.0005) \text {. Effects lasted at } \\
\text { least } 6 \text { months post- } \\
\text { rehabilitation. }\end{array}$ \\
\hline
\end{tabular}




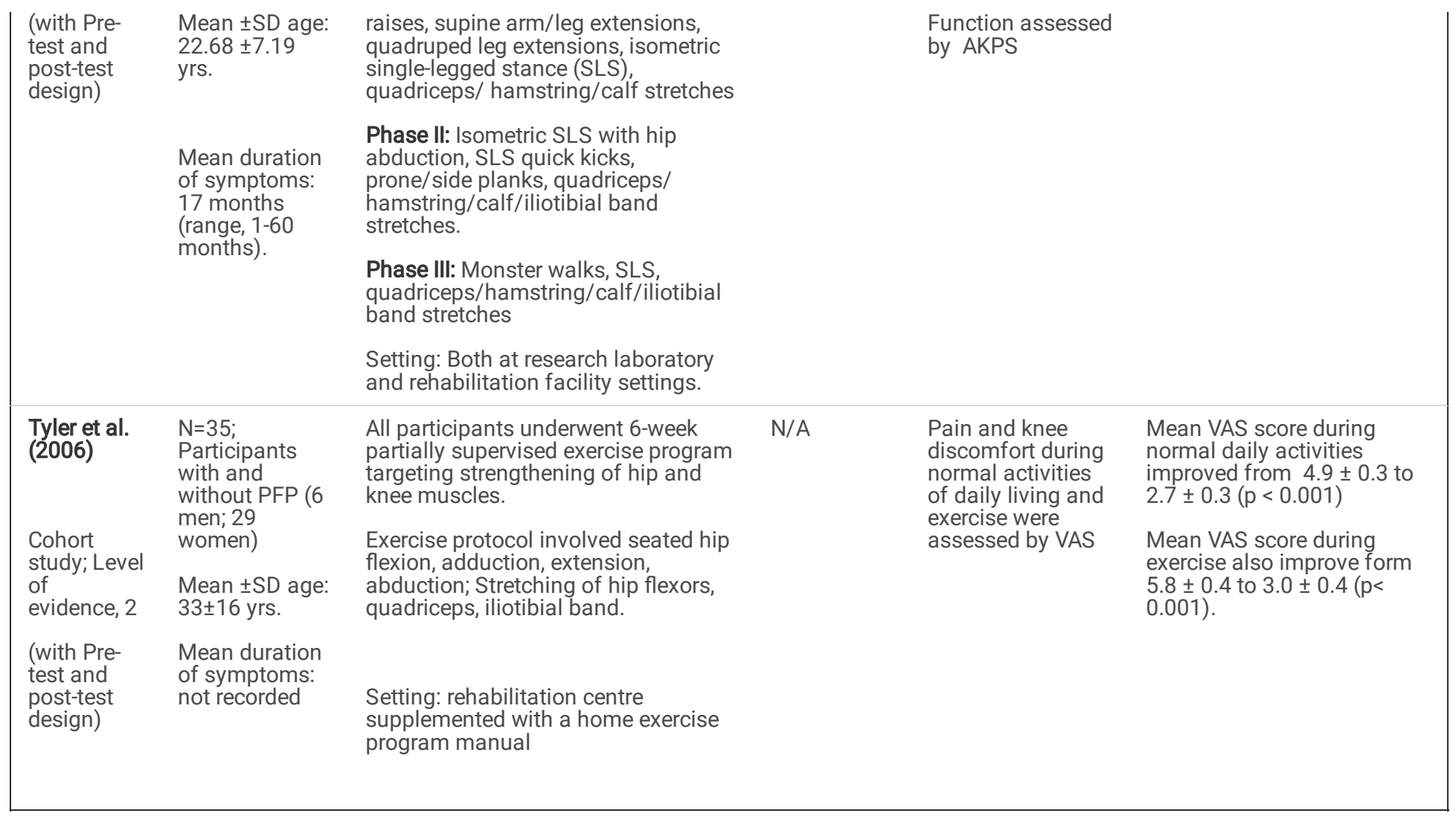

\section{Figures}




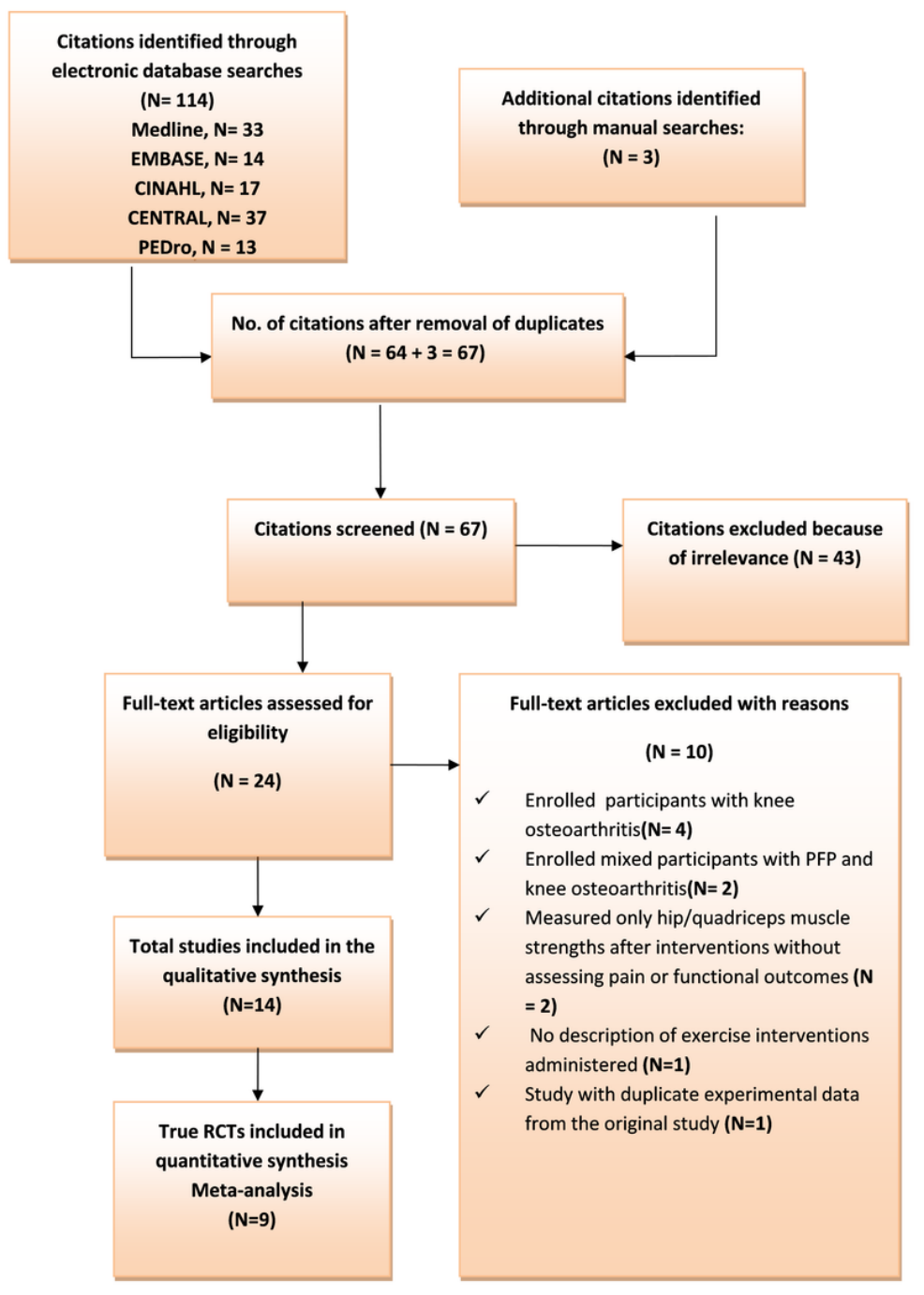

Figure 1

PRISMA flow chart for articles search strategy, screening and eligibility evaluation 
Dolak et al. 2011

Dolak et al. 2011

Dolak et al. 2011

Comparative effect of hip Vs. quadriceps strengthening on PFP (Meta-analysis)

Baldon et al. 2014

Khayambashi et al. 2014*

Khayambashi et al. 2014*

Total (fixed effects)

Total (random effects)

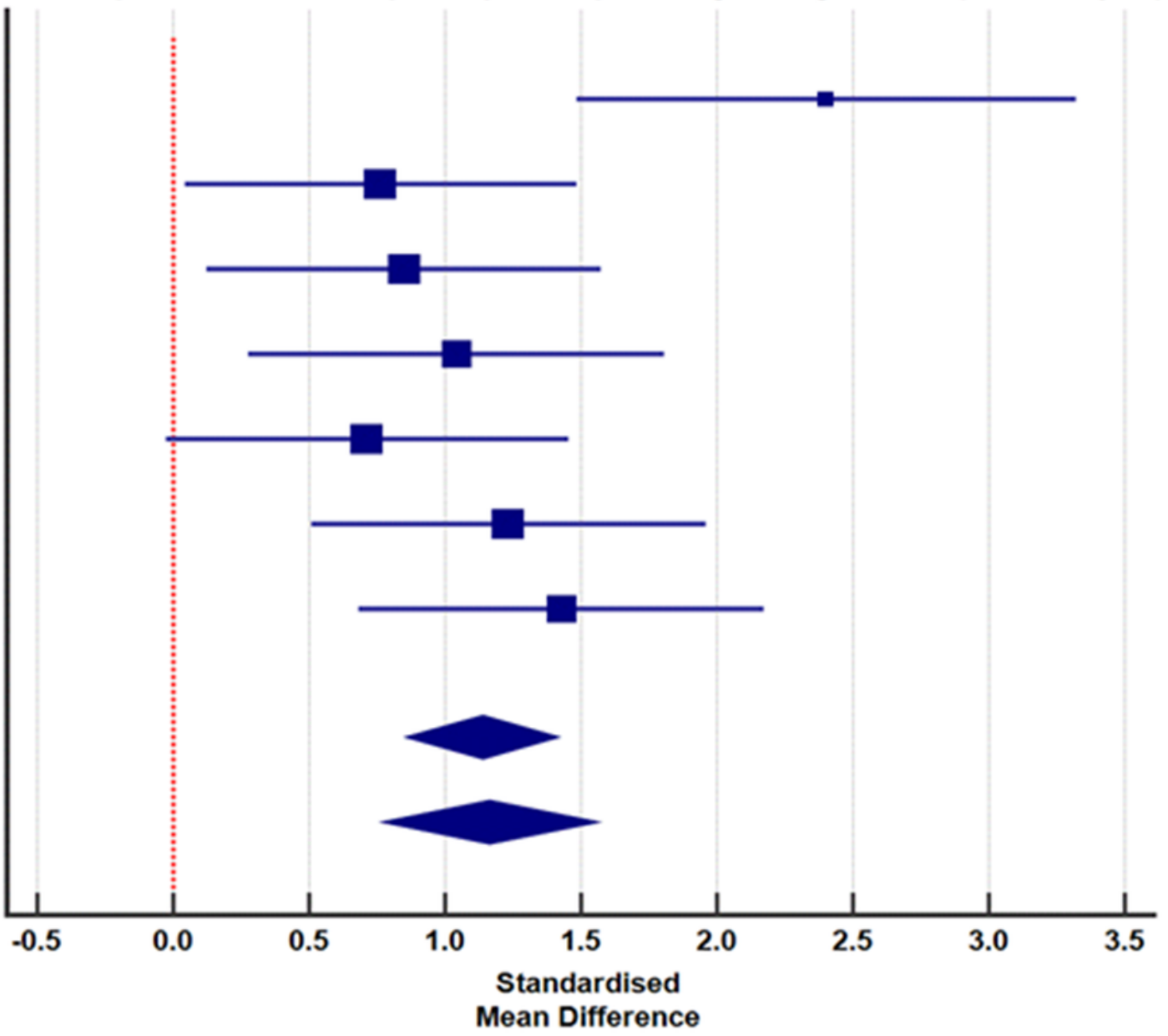

Figure 2

Hip versus quadriceps strengthening on PFP 
Comparative effect of hip Vs. quadriceps strengthening on knee function (Meta-analysis)

Dolak et al. 2011

Dolak et al. 2011

Dolak et al. 2011

Baldon et al. 2014

Baldon et al. 2014

Khayambashi et al. 2014*

Khayambashi et al. 2014*

Total (fixed effects)

Total (random effects)

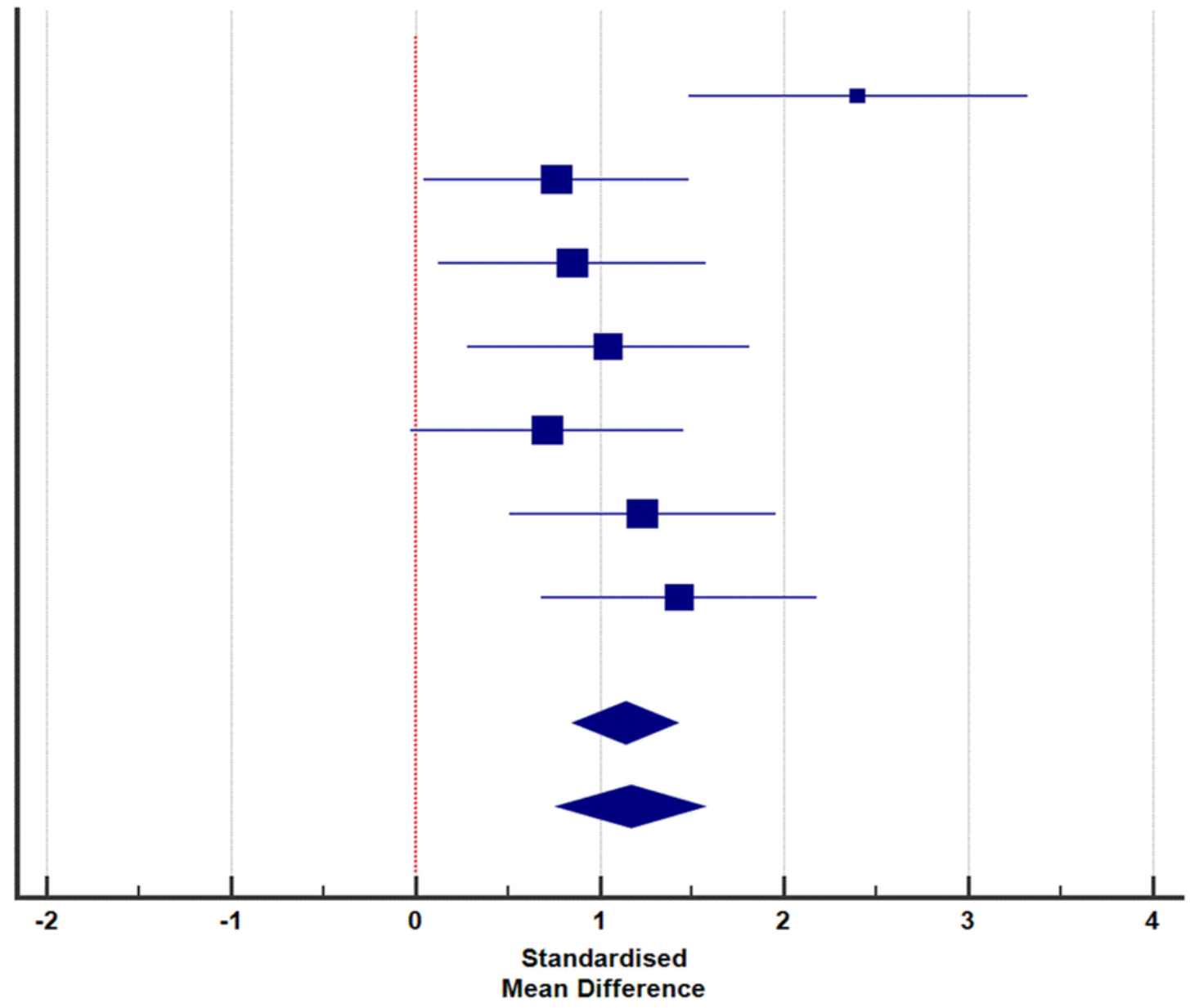

Figure 3

Comparative effect of hip versus quadriceps strengthening on knee function 
Nakagawa et al. 2008 Nakagawa et al. 2008 Nakagawa et al. 2008 Nakagawa et al. 2008 Nakagawa et al. 2008 Nakagawa et al. 2008

Song et al. 2009

Fukuda et al. 2010

Fukuda et al. 2010

Fukuda et al. 2012

Fukuda et al. 2012

Fukuda et al. 2012

Fukuda et al. 2012

Fukuda et al. 2012

Fukuda et al. 2012

Ismail et al. 2013

Total (fixed effects)

Total (random effects)

Surplus effect of hip-quadriceps Vs. quadriceps strengthening on PFP (Meta-analysis)

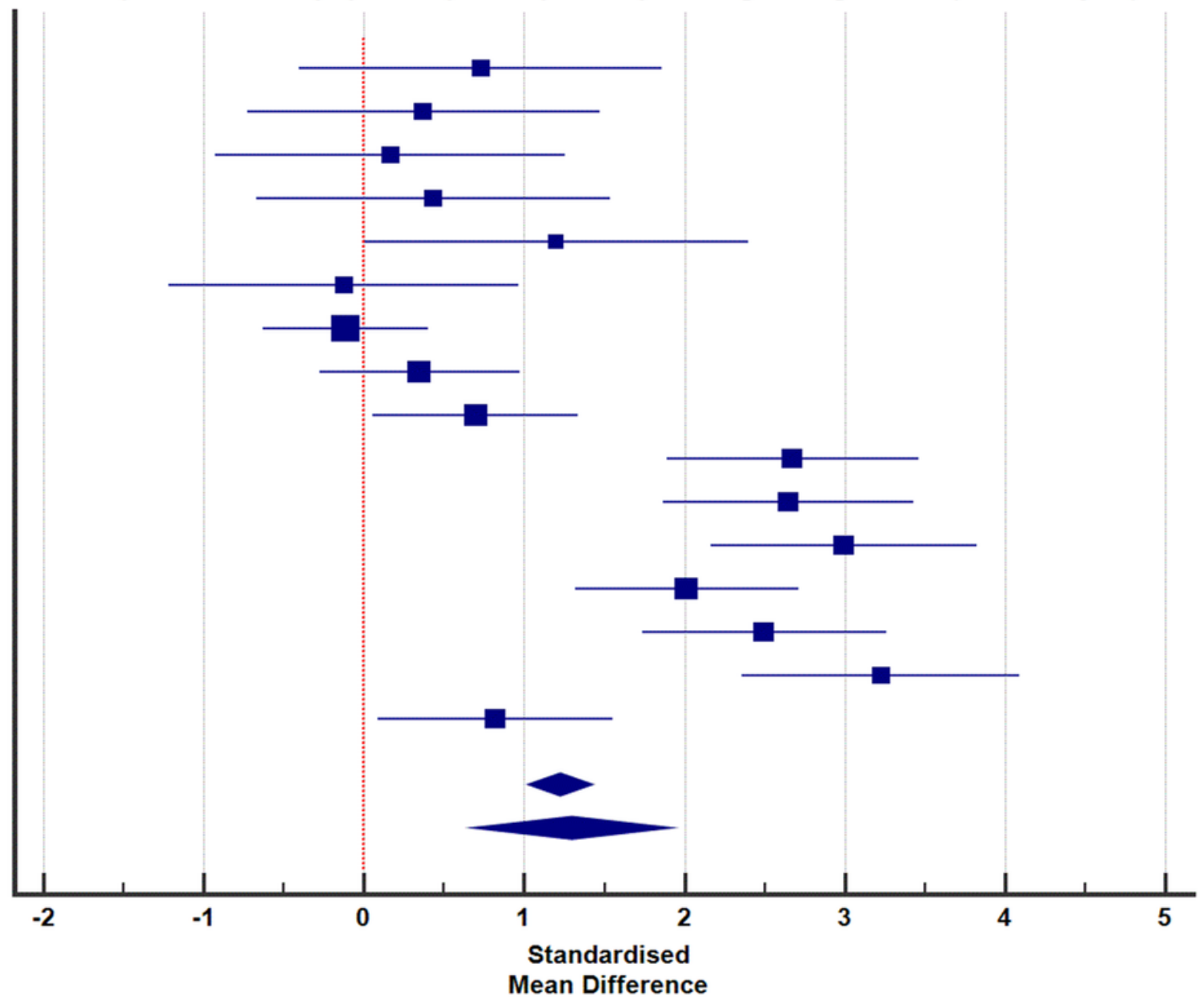

Figure 4

Hip-quad strengthening results in significant pain improvements compared to the standard quadriceps strengthening alone. 
Surplus effect of hip-quadriceps Vs. quadriceps strengthening on knee function (Meta-analysis)

Fukuda et al. 2010

Fukuda et al. 2010

Fukuda et al. 2012

Fukuda et al. 2012

Fukuda et al. 2012

Fukuda et al. 2012

Fukuda et al. 2012

Fukuda et al. 2012

Ismail et al. 2013

Total (fixed effects)

Total (random effects)

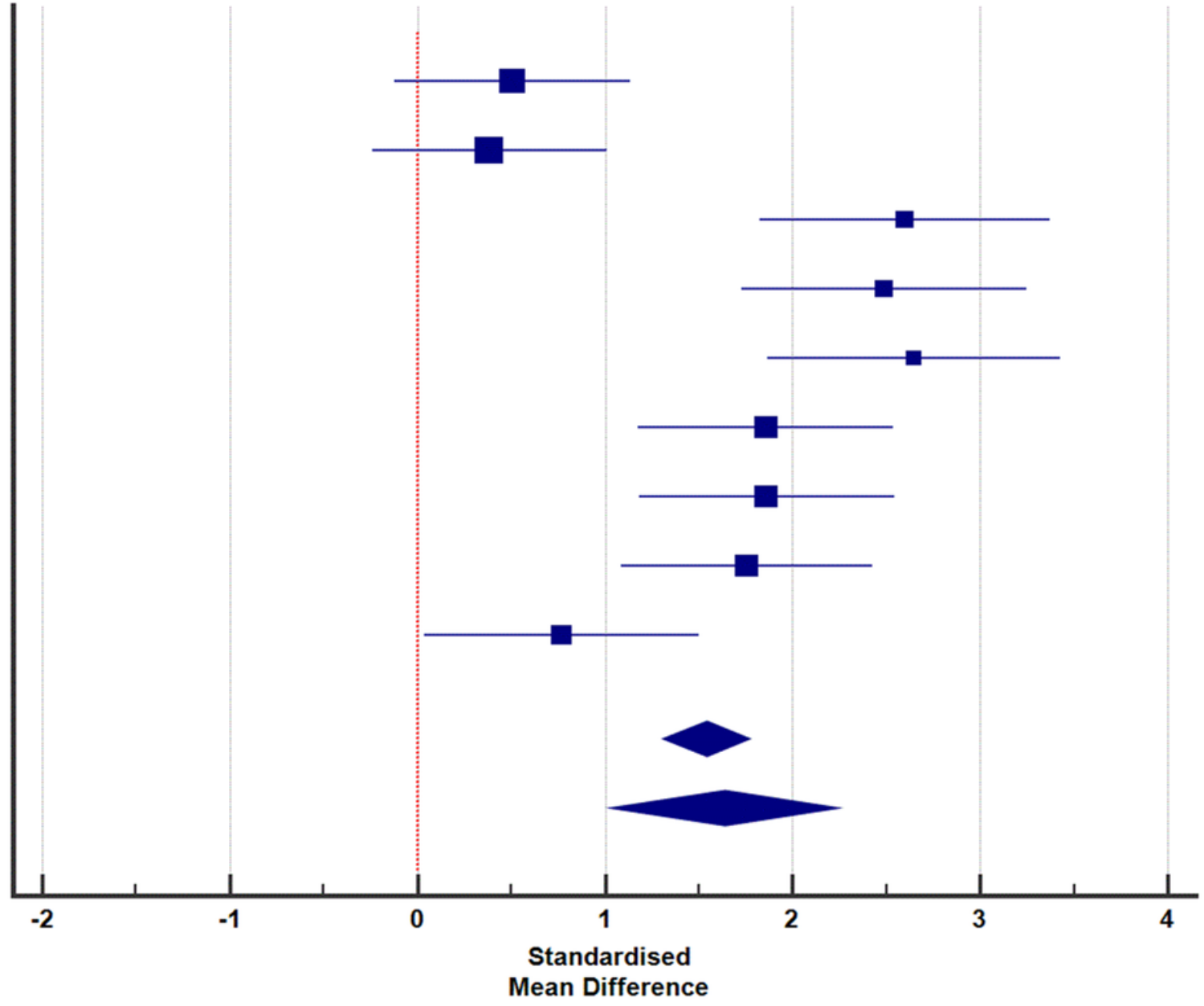

Figure 5

Hip-quad strengthening resulted in a greater functional improvement than the standard quadriceps strengthening alone.

\section{Supplementary Files}

This is a list of supplementary files associated with this preprint. Click to download.

- PRISMA2020checklist.pdf 